\title{
THE DESIGN SYSTEM AND ITS FORMAL INFERENCE IN LOGO DESIGN
}

\author{
Fouad Ahmed Shallal AL-SAMARRAEE ${ }^{1}$
}

\section{Istanbul / Türkiye \\ p. 729-749}

Received: $26 / 11 / 2021$
Accepted: 11/12/2021
Published: 01/01/2022

This article has been scanned by iThenticat No plagiarism detected

\begin{abstract}
:
The communicative and cultural achievement is represented by an activity with adopted formulas confirmed by compliance and flexibility that enables it to keep pace with the creative path in the age of infomedia and contemporary digital publishing programs. The explanatory space, in its intellectual and technical forms, is based on logical foundations that work on creating latent patterns and patterns that enhance the purpose of its existence. And the system in art in general and design in particular represents a mechanism for arranging work vocabulary on the basis of principles that usually refer to a system that checks the state of damage between the design work vocabulary. The system stems from those defects embodied in expressive formats that are linked to concepts and ideas through the organization of different vocabulary within the workspace that have specific characteristics that reflect a particular idea and are linked to the specificity of the required utilitarian functional nature. The lesson of the system is not only to reach the relationships that exist between the vocabulary in their embodiment of the concrete form, but it lies on a much deeper level than that, which is the level of significance.

Where the formal characteristics of the product of organizational relations reflect patterns that often express their environment or are the result of those organizations with semantic reading, and the difference in the nature of the formulation of these organizations comes from the effect of the overlap of several different factors (cultural, social, religious, civilizational, functional).

The design thought derives its primary material through this overlap to start the system according to the rational methods in the drafting process. To evaluate things and this is the rule of logic.

From here the researcher sees that the principle of the system and its relation to the degree of formulation of the form, and the extent of variation of this formulation is due to the mental readiness in the process of organization and innovation, to be a specific formal inference related to its basic function and its structural composition in the designs of logos, so the idea of research and formulation of the research problem came according to the following question: Is there a role for the design system in formal inference in logo design? The importance of the research was formulated through:
\end{abstract}

http://dx.doi.org/10.47832/2717-8293.15.50

1 iD Dr. , Baghdad University, Iraq, foad.ahmed@ cofarts.uobaghdad.edu.iq 
-Informing those interested in the design issue, for the purposes of developing the mechanisms of their technical work.

-To benefit scientific and research institutions, as well as the press, publishing houses, and advertising agencies. The aim of the research lies in: Knowing the role of the design system in formal inference in the design of logos, and defining the limits of research, which lies in the objective limit: the design system and formal inference in the design of logos Spatial limit: some Examples of global logos that enhance the current research, And the time limit for the designed logos from (2019-2021), and definitions of the following terms were defined: design system and formal inference..

Key words: The Design System, Logo Design, Formal Inference. 
النظام التصميمي والاستدلاله الشكلي

في تصميم الشعارات

\section{فؤاد أحمد شلال السامرائي}

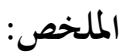

يتمثل المنجز التخاطبي التواصلي الثقافي بنشاط ذو صيغ متبعة تتوكده المطواعية والمرونة التي تمكنها من مسايرة الركب الإبداعي في عصر الانفوميديا وبرامج النشر الرقمي المعاصر، وهذا النشاط يحتكم لنظام وقواعد شكلية

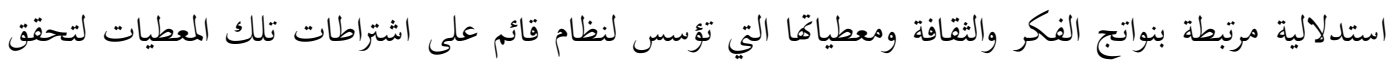
أعلى قدر من المساحة التوظيحية بشكليها الفكري والتقني على وفق أسس منطقية تعمل على أحداث انسات انساق

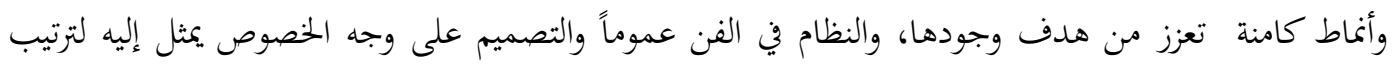
مفردات العمل على وفق أسس تشير في العادة إلى نظام محقق حالة التالف بين مفردات العمل التصميمي.

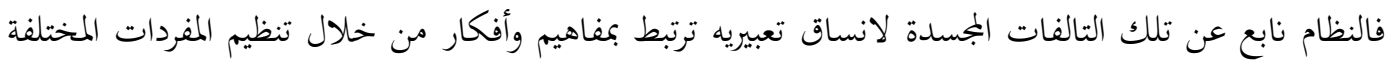

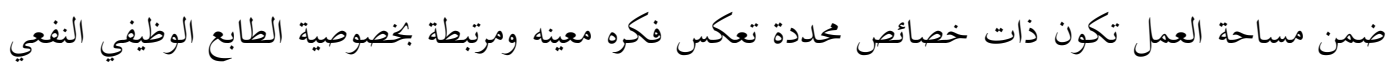

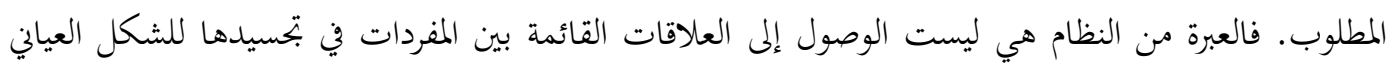

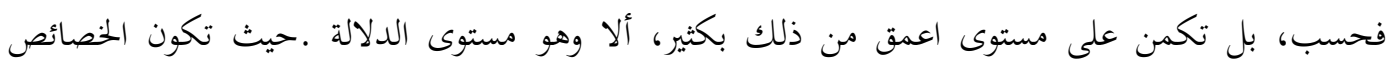

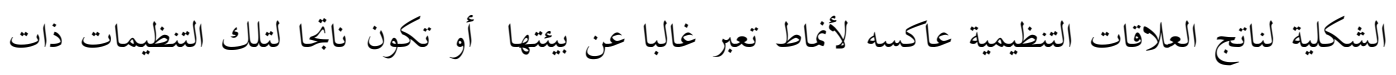
الاسقراء الدلالي، ويأتي الاختلاف في طابع الصياغة لهذه التنظيمات من اثر تداخل عدة عوامل مختلفة (ثقافية، اجتماعية، دينيه، حضارية، وظيفية). فالفكر التصميمي يستمد مادته الأولية من خلال هذا التداخل ليبتدئ به النظام على وفق الطرق العقلانية في

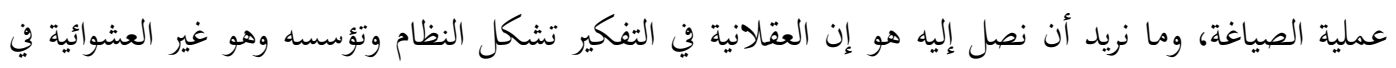

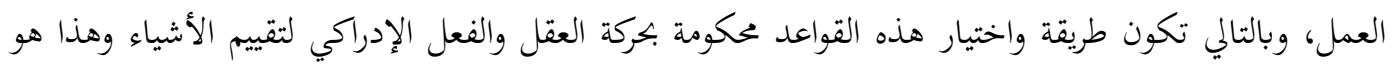
حكم المنطق. من هنا يرى الباحث ان مبدأ النظام وارتباطه بدرجة صياغة الشكل form ، ومدى تفاوت هذه الصياغة إنما

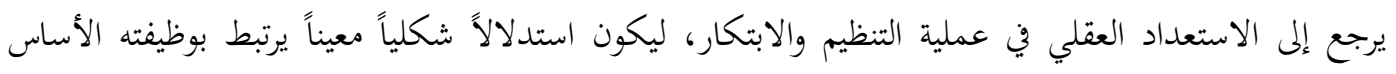
وتكوينه البنيوي في تصاميم الشعارات، فجاءت فكرة البحث وصياغة مشكلة البحث على وفق التساؤل التالي:

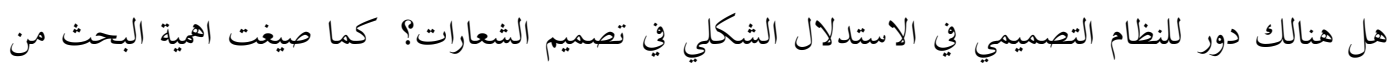

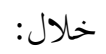

- إفادة المهتمين بالشأن التصميمي، لأغراض تتعلق بتطوير آليات عملهم الفني.

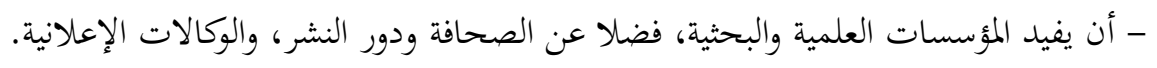
الكلمات المفتاحية: النظام التصميمي، تصميم الشعارات، الاستدلال الشكلي. 
تعرف دور للنظام التصميمي في الاستدلال الشكلي في تصميم الشعارات، وحددت حدود للبحث والتي تكمن الحد الموضوعي: النظام التصميمي والاستدلال الشكلي قي تصميم الشعارات الحد المكاني: بعض من نماذج الشعارات العالمية التي تعزز

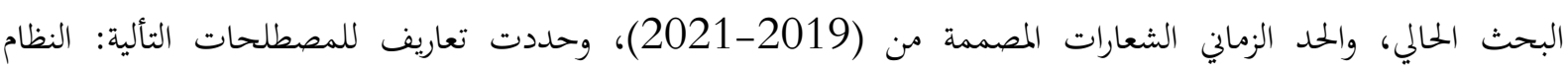
التصميمي والاستدلال الشكلي.

يؤلف النظام والتنظيم تكويناً محكم يميط بجميع المعطيات الداخلة ضمن العملية التصميمية من عناصر وأسس فضلاً عن

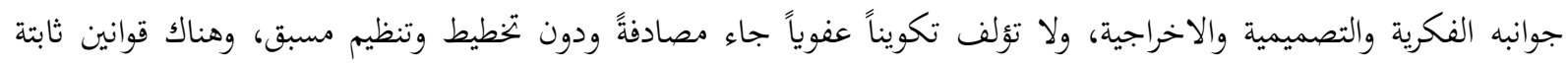

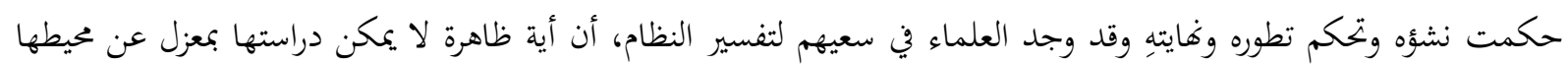
وعن الظواهر الأخرى التي تحيط بها، فهي جزء من كل لا يتجزأ من المحيط بكل مفرداته،ويرتبط هذا النظام بالطبيعة والكون،

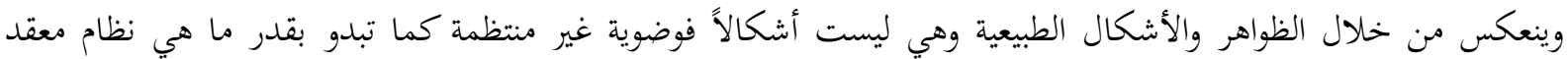
ودقيق، وهو ما يعبر عنه بالأشكال الهندسية المجردة كالخط، السطح، المربع، الدائرة، الأسطوانة، أي أن هذا النظام يرتبط بالطريقة العقلانية للتفكير، ومن هنا نجد أن الإنسان قد رصد طبيعة النظام في كثير من مجالات الحياة، وحاول أن يضمنها في مختلف نوابته إنها

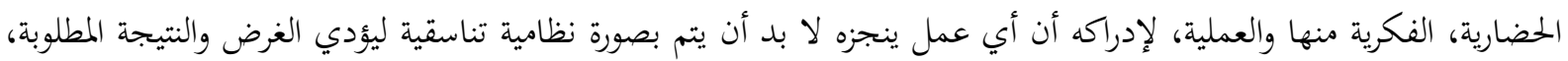
وقد انعكس هذا المفهوم في مجال الفكر والعلوم بشكل دقيق ومباشر وبقواعد منطقية وأسلوب منهجي. لإدري. أما في الفن فقد كان تجسيد النظام من خلال تنظيم مفردات مختلفة ضمن العمل الفني وفقا لخصائص محددة تعكس فكرة

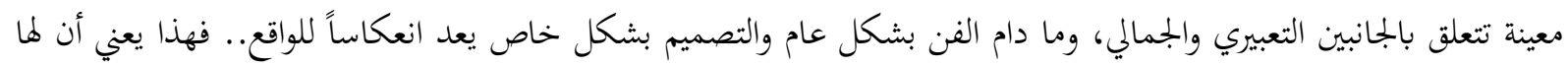

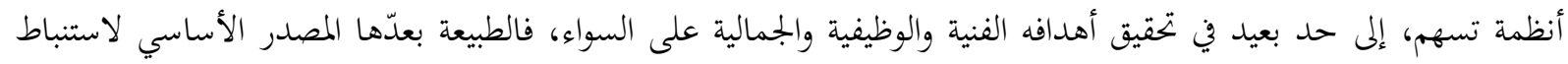

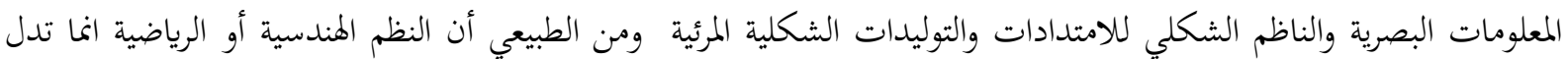
على التكوين الشكلي وما تتوالد عنه من دلالات تعبيرية تتناول المظهر الشكلي بكل تمثيلاته لاستباط المعلومات البصرية والتكوين لامتدادات وتوليدات شكلية دلالية، ومما تقدم وجد الباحث مسوغاً لصياغة مشكلة بحثه من خلال التساؤل التالي: ماهو دور النظام التصميمي في الاستدلال الشكلي في تصميم الشعارات.

- الأهمية النظرية: بناء إطار منهج معرفي يتناول فيه النظام التصميمي وكيفية بتحسيده للاستدلال الشكلي في تصميم الشعارات

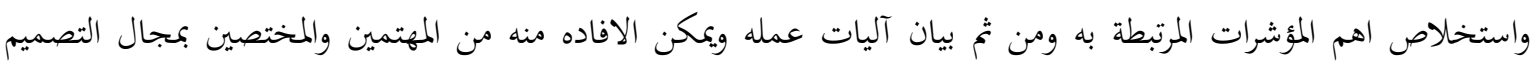
الكرافيكي نظرياً. - الأهمية التطبيقية: مساهمة وتنمية وتطويرالمهارات العملية للمشتغلين والمصممين بالجانب الكرافيكي وتسليط الضوء لهم على آليات تكون النظام التصميمي وكيفية تجسيد الدلالات الشكلية في تصميم الشعارات. 
حدود البحث:

الحدود الموضوعية: دراسة النظام التصميمي والاستدلال الشكلي في تصميم الشعارات.

الحدود المكانية: الشعارات المصممه (امريكا، اسبانيا، فرنسا،الامارات العربية المتحدة ) . .

الحدود الزمانية: 2019 - 2021

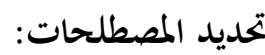

النظام فلسفياً: هو مفاهيم العقل الأساسية، ويشمل الترتيب الزماني، والترتيب المكاني، والترتيب العددي، والسلاسل والعلل

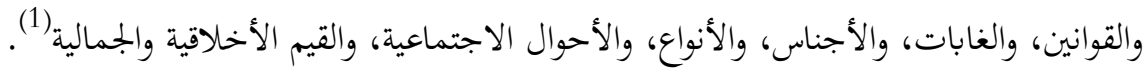
النظام لغوياً: نظمه ينظمه ونظمه ونظاما فأنتظم وأنظم، ونظمت اللؤلؤ أي جمعته في السلك والتنظم مثله، ومنه نظمت الشعر ونظمته، وأنظمت فيه الشيء من خيط وغيره وكل شعبه منه واصل ونظام كل امر ملاكه، والجمع أنظمه وناظم ونظم (2). النظام اصطلاحا: (n)

النظام: هو مجموعه من الأجزاء التي تعمل مع بعضها البعض في علاقة نظامية وفقا لغرض معين لكل من المبادئ والأفكار ينجز أو يرتب في بتحانس وتناغم المرتبة والمترابطة وظيفيا.

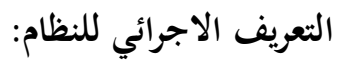

النظام: هو عملية ذات منهج متسلسل ومتناسق لتشكيل بجموعة عناصر داخل الفضاء التصميمي بطريقة تجسد الغرض

والوظيفة التصميمية في الشعار.

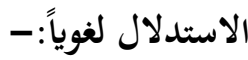

عرفه الجرجاني: الاستدلال: هو تقرير الدليل لإثبات المدلول. (3)

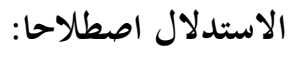

- - الدلالة (كدراسة أو علم المعنى).

- - استنتاج قضيّة مجهولة من قضيّة، أو من عدة قضايا معلومة. (5)

- فعل ذهني مؤلف من احكام متتابعة، اذا وضعت لزم عنها بذاتما حكم اخر لغيرها(6)

الاستدلال الشكلي اجرائياً: - الئ

هو فعل يقر دليلاً شكلياً كلمة لاحتواء الوسيط المستخدم وتوجيهه في وجهة معينة تفرض بالضرورة إمكانات تعبريية معينة بنظام ذو مواصفات، ويدل على تنظيم عناصر الوسيط المادي التي يتضمنها العمل وتحقيق الارتباط المتبادل بينها. 
يعتمد تحقيق النظام على مجموعة من العناصر المرتبطة ضمن شبكة من العلاقات التبادلية بين المكونات التي تحتكم له، ويعد النظام ألية تنظم تكوين الشكل وتنقله من واقع غير ملموس إلى واقع ملموس متضمن العناصر الموجودة والمحيطة للمنجز التصميمي ويعطيها قيمة بتسد ماجاءت به العناصر التصميمية من هدف وظيفي، ويمثل النظام في الفن والتصميم إليه لترتيب

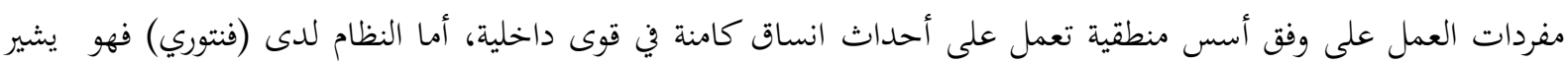

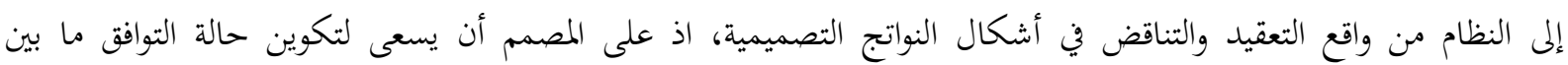
المتناقضات ويكيف عناصر تصميمية بنائية في تصميم المنجز، والنظام مبدأ أساس في التصميم وممثلاً للعملية الفاعلة التي تدور

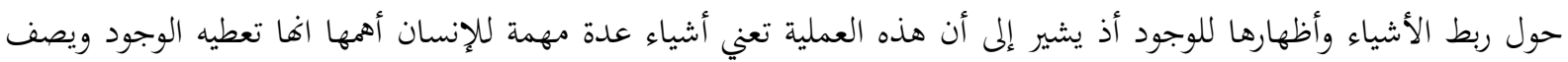

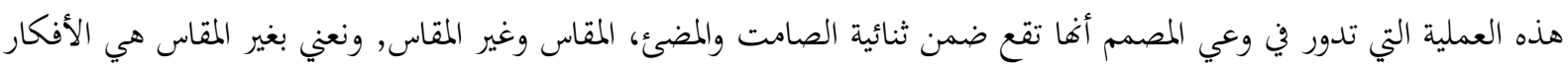

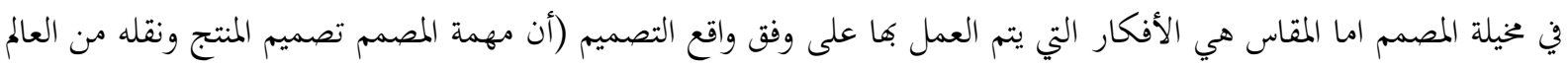
الصامت إلى العالم المضئ والنظام يقع خلف هذه الثميل الثنائية). إن أهمية النظام هذه تشمل مجالات عدة على اختلاف طبيعتها، أذ يشير (Arnhem) أنه أساسي ولا غنى عنه في

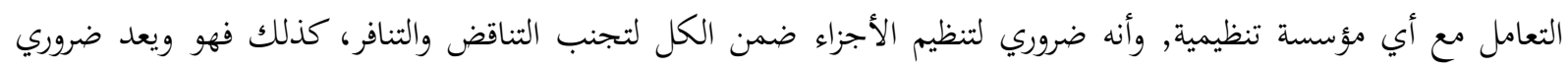

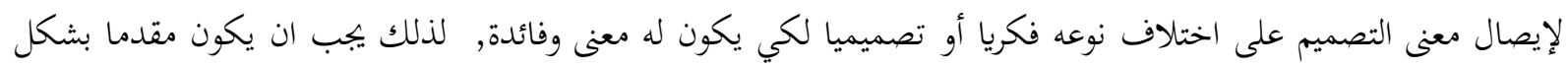
نظامي وبذلك يكون قد حقق التقبل لدى المتلقي. وبذلك فإن النظام كيان متكامل من المنجز التصميمي، ويتكون من ونس أجزاء

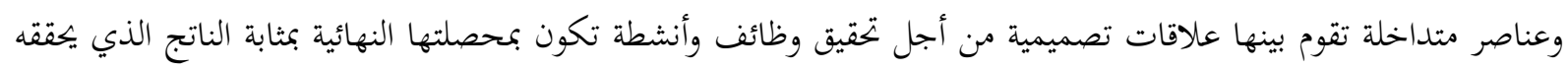
النظام كله. كما تشير هذه المفاهيم في مجملها إلى معنى النظام بأنه الأسلوب الذي ينتظم به عدد من العناصر والمفردات في علاقات تخدم بعضها البعض اذ ان الشكل يبدو في وحده كلية تمثل هذا النظام (7). ومما تقدم يرى الباحث أن احدى أهم مفاهيم النظام هو كونه يأتي كوسيلة لإنجاز التصميم بشكل منهجي ومنطقي وذو صيغة متسلسلة ومتتابعة في التصميم أحيانا، ويشمل طريقة وعملية مزج العناصر في تكوين موحد للحصول على لئى حالة التجانس،

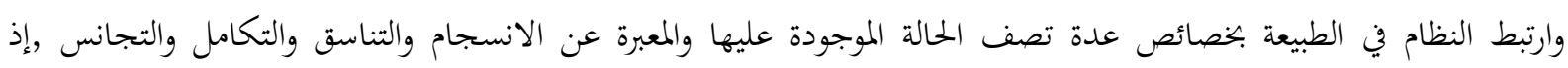

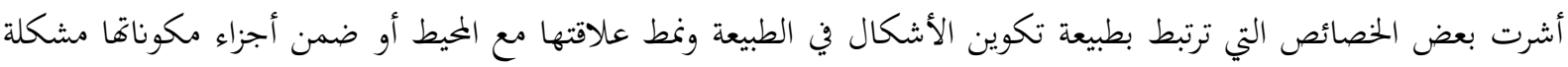

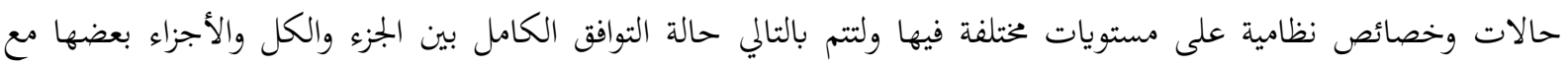
البعض الآخر، لقد تركزت هذه الخصائص في خاصيتين الاولى تشير إلى الوحدة التصميمية والثانية تؤدي اليها وهي خاصية التوازن التصميمي. إذ ان مفهوم الوحدة التصميمية ضمن الطبيعة وأجزاءها عدت من قبل بعض المصممين أساسا لفلسفتهم في العمل التصميمي وفي نظرقم إلى الحالات المختلفة في جوانب الحياة.

الدلالة مفهوماً: - 20 - n

علم الدلالة هو تفسير المعاني والرموز والإشارات، حيث يهتم بدراسة أنظمتها وآليات تكوينها، وقد تبلور هذا المفهوم بعد تيارات الحداثة التي ظهرت في ستينيات القرن العشرين "البنيوية وما بعدها" بوصفها ظاهرة لفهم العالم وتفسيره ودراسة الأنظمة

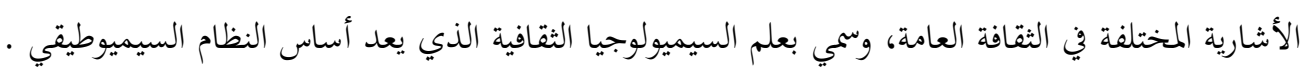


وكلمة الدلالة "السيميانتك" Semantique مشتقة من الأصل اليوناني "سيميو" أي علامة، ويرجع مصطلح

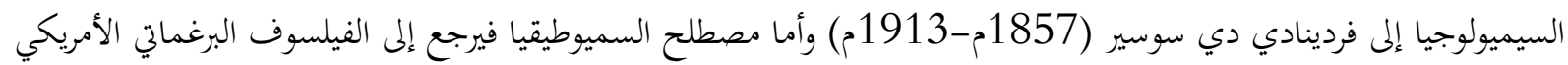

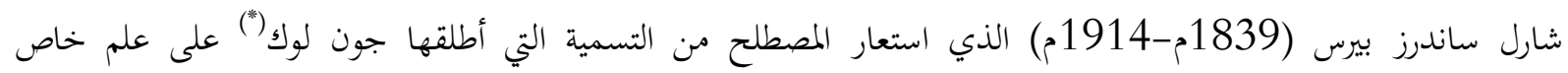

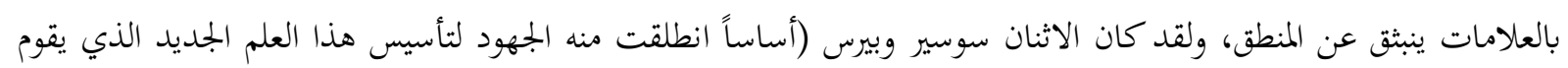
على دراسة أنظمة التواصل البشري)(8)، حيث ركز سويسر كما يقول جيرو على الوظيفة الاجتماعية للإشارة (العلامة) بينما ركز بيرس على الوظيفة المنطقية. والمظهرين على صلة حميمة، والكلمتان سيمولوجيا وسيميائيات تعطيان اليوم نظامًا واحدا. فالسيميولوجيا هي علم الأشارة الدالة مهما كان نوعها واصلها، وهذا يعني إن النظام الكوني بكل ما فيه من إشارات

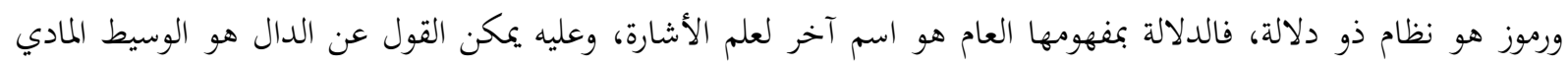
للمدلول. والربط بين الدال والمدلول يعد صفة تعاقدية مبدئية هذا العقد جماعي منقوش في زمن طويل. فاللغة نظام من العلامات،

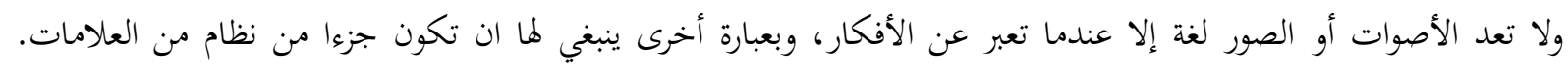

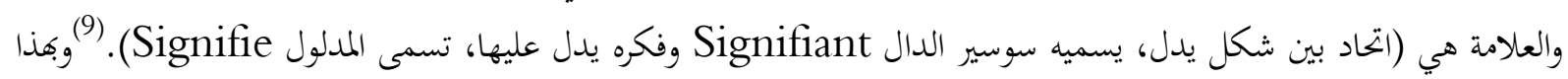

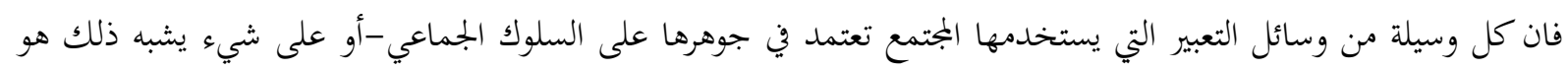

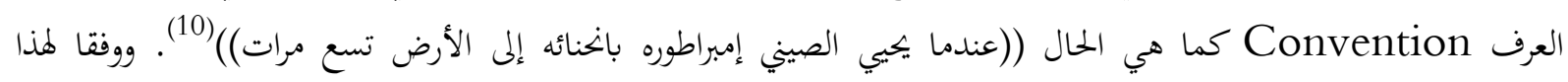

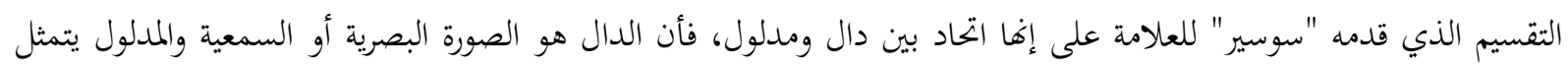

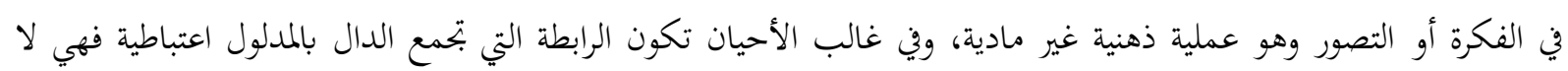

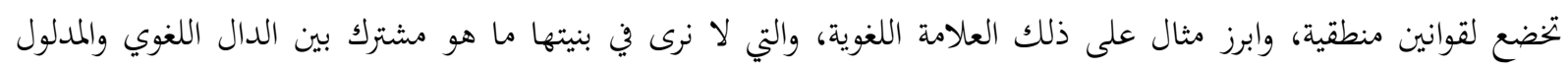

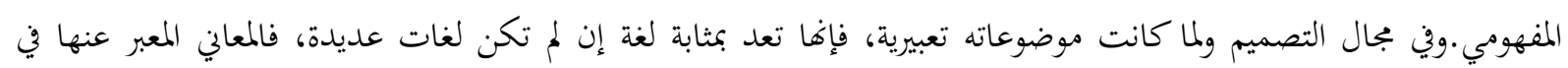
التصميم يمكن ترجتها إلى ألفاظ.

والعمل التصميمي يقوم على محاكاة الواقع ذو الوظيفة النفعية، وعليه فالمصمم ينتقي بعضاً من عناصر الواقع ويقدمها على ترئ

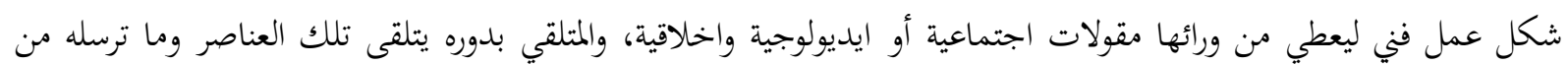
علامات، فيردها في ذهنه إلى مرجعها الحقيقي.ويمكن القول بان المرجع هو "تخيل المتخيل" المتماثلة طبعا من متلقي إلى آخر.

الدلالة الشكلية:

يذهب نقاد النزعة الشكلية إلى فهم طبيعة الفن المعاصر في وقت ما عند التفكير في موضوع الشكل نجده ينطوي على

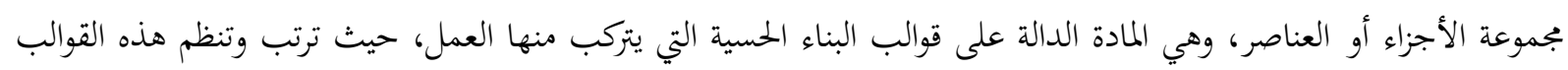

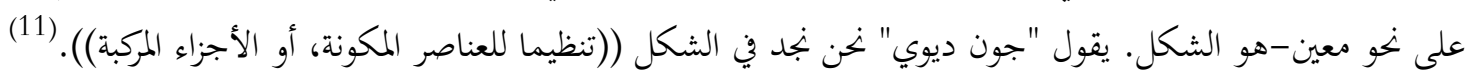
فالشكل هو جمع لعدة عناصر متحدة في كيان واحد له قيمة الإدراك العقلي. ويرى "هربرت ريد"، إن لفظة الشكل في

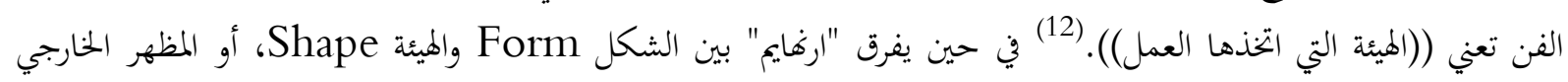

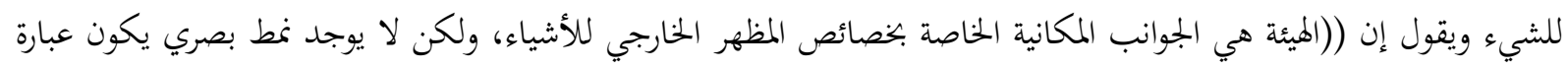

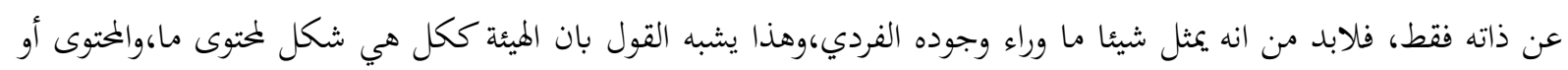

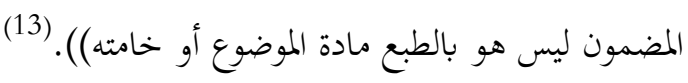
ويعد استخدام "ارغايم" لمفهوم "الشكل" استخدام يتضمن الميئة والمضمون. وعليه (فالشكل بالمعنى الإدراك ضروري

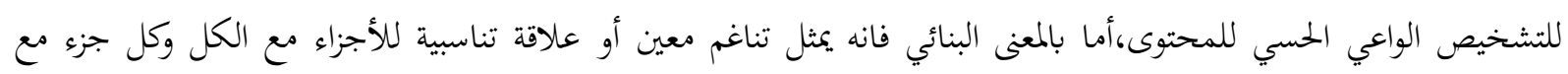


الآخر).(14) فالشكل يشير إلى طريقة خاصة في النظر إلى الأشياء والإحساس بها من خلال التركيب الخاص للعناصر،والتي تعد الجوهر الفعلي أو الموضوع الفني نفسه.

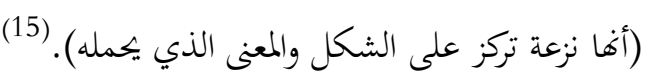

ولعل تركيز "لانجر" على الشكل وأهيته يرجع إلى إدراكها العميق للوظائف التي يقوم بها الشكل. وهذا السبب جعل من

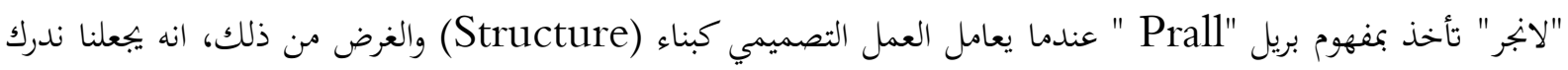

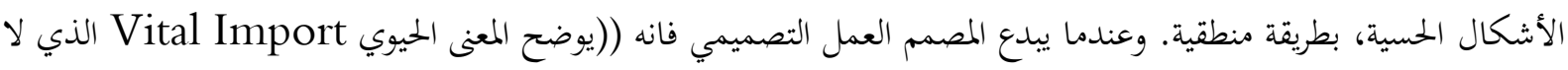

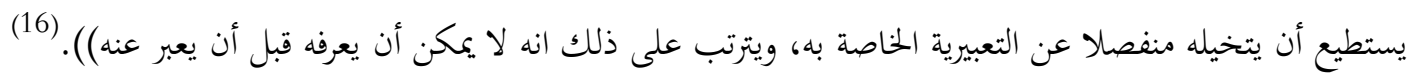

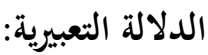

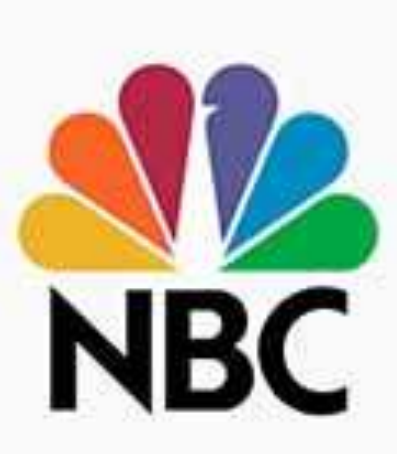

إن السيميائية تقوم على العلاقة بين العلامة والدال والمدلول، فالعلامة مكونة من دال

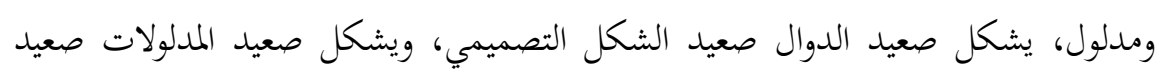
المحتوى، والعلاقة بين الدال والمدلول، علاقة وضعية اصطلاحية، وهي ضرورة لتحقيق التواصل الذي عبر عنه أحيانا بالبيان أحيانا بالإخبار.

وإذا أخذنا نظاما مثل التصميم، نجد انه يتكون من ثلاث عناصر أساسية: العنصر

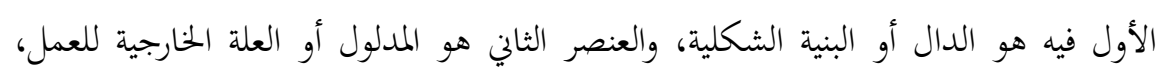

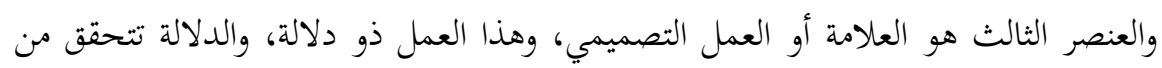
خلال قدرة الدال التعبيرية في توصيل الأفكار.

وعليه فالقدرة التعبيرية التي يتضمنها النص التصميمي يتطلب إدراك العالم الخارجي ((فالمعاني التي تعبر عنها النصوص

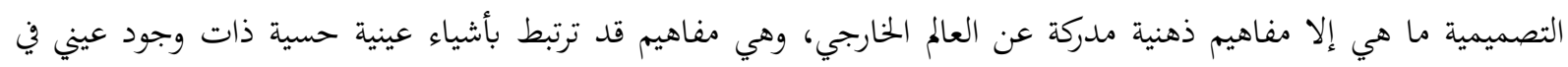

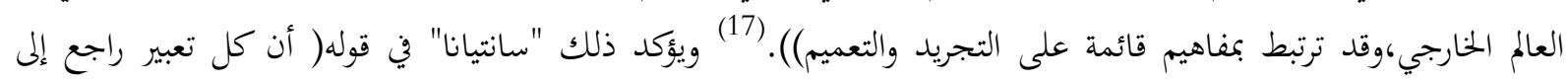

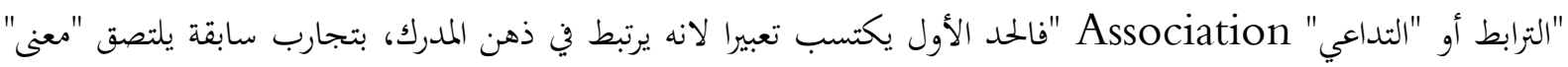

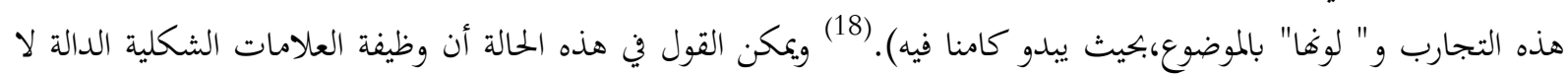

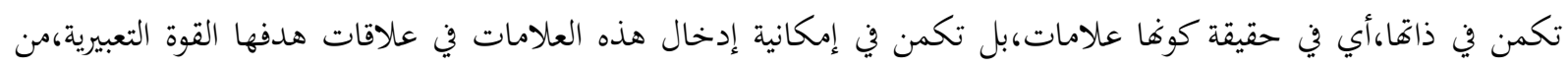

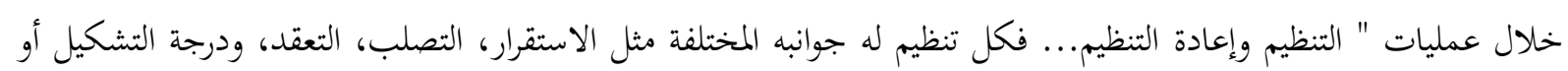
غيرها من الخصائص، وينتج التنظيم عن التفاعل، وإعادة التفاعل بين الكائن والبيئة" (19).

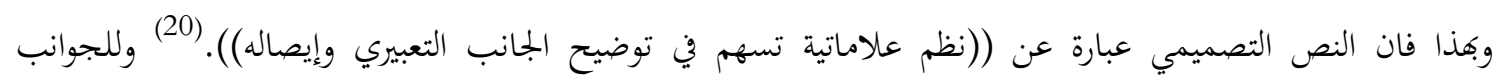
التعبيرية جذور متأصلة، في الأوجه المادية والشكلية والتصويرية للعمل. وهذه العوامل الأخيرة، عندما تحلل، تقدم شواهد تساعد على نسبة المضمون التعبيري إلى العمل، وعليه فان العمل التصميمي بوصفه علامة دالة يعتمد على منظومة ثلاثية من العلاقات بين الأطراف التألية: (مادة التعبير والمتمثلة بالألوان والمسافات، وأشكال التعبير وهي التكوينات التصويرية للأشياء، ومضمون التعبير وهو

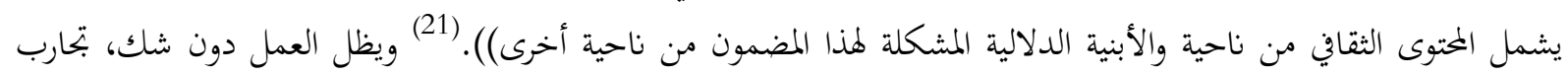

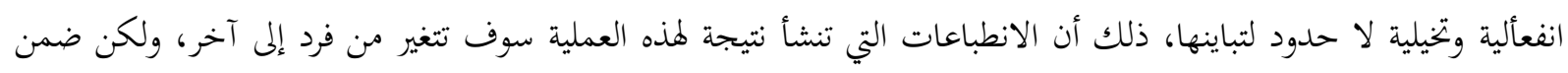

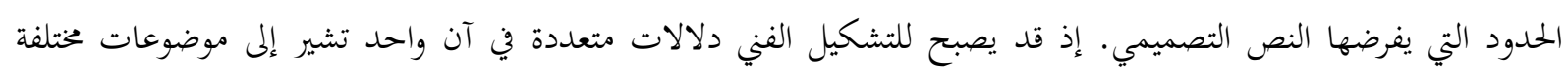


وبمعان متنوعة مما يسبب اضطرابا كبيرا للتنوعات الظاهرة في مضمونه المعبر عنه، إلا أها تبقى في سياقها العام مترابط تحمل أهمية

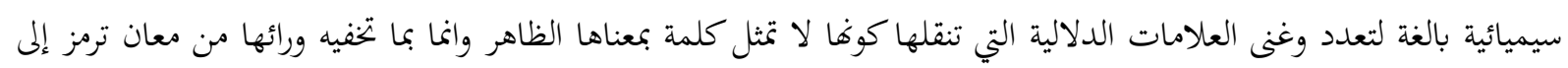

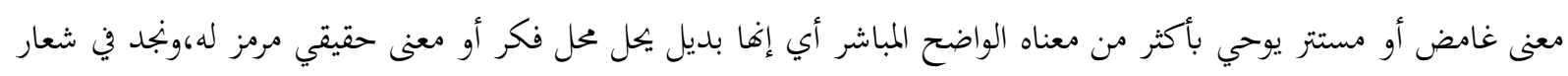

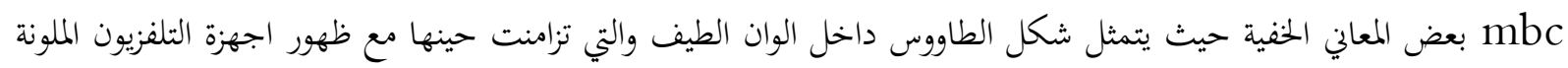

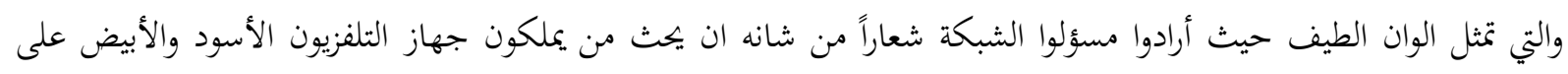

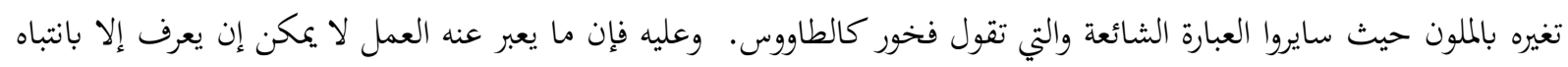

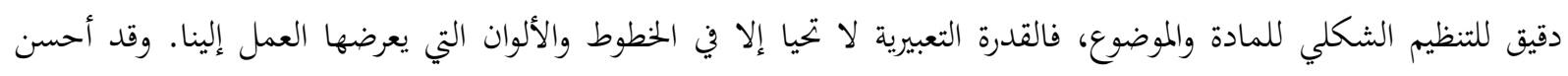

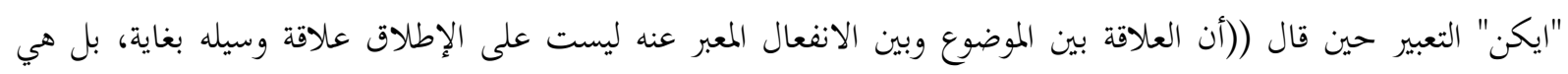

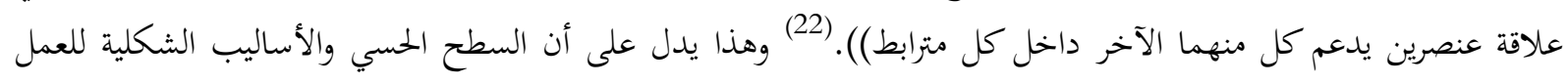

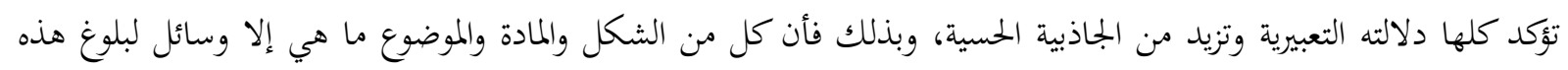

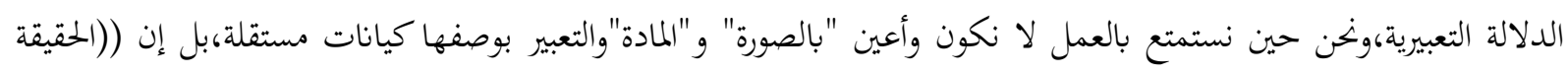

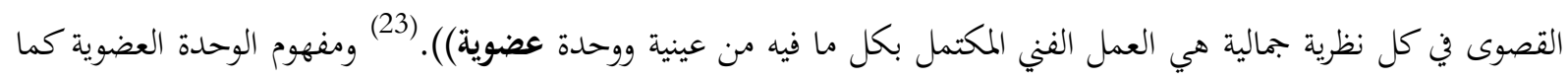
يستخلصها "عبد الرضا بهيه "من رأي "ستولينتز"(24) هو : 1. أن يكون كل عنصر في العمل الفني ضروريا لقيمته التعبيرية والجمالية. 2. أن يكون كل ما هو لازم لبناء القيمتين موجودا في العمل الفني. 3. إن تغيير أي جزء يؤدي،لا إلى حدوث فارق فحسب،بل إلى حدوث فارق مهم،خاصة إذا كان هذا الجزء

$$
\text { أساسيا وحيويا. }
$$

4. إن هذا الفارق المشار إليه إنما يكون في القيمة الجمالية للموضوع. ولا شك إن ما يهمنا في هذا السياق أن نؤكد على إن رؤية المصمم وأيديولوجيته ووجهة نظره واتحاهاته وقيمه وتصوراته

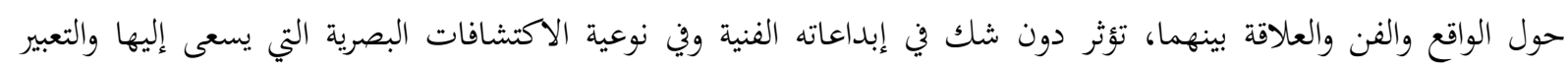
التشكيلي الذي يفضي إلى الدلالة الوظيفية للعمل أيضا.

\section{الدلالة الوظيفية: - 20 - n}

ترتبط الدلالة الوظفيية إلى حد ما بعملية الابتكار والتي تعني عمل الشيء الجديد، إرضاء لبعض الاحتياجات الإنسانية.

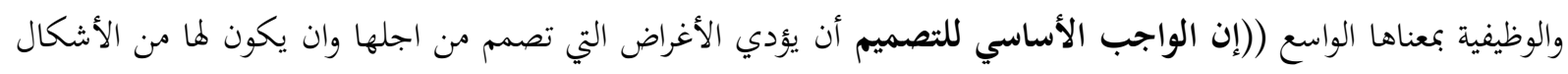

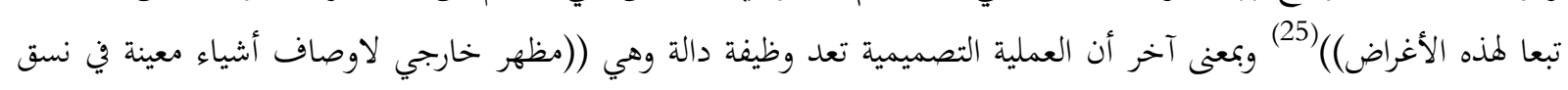
معين من العلاقات)(). (26)

وفي ضوء ذلك يمكن القول ان جوهر الوظيفة مرتبط بجوهر العملية التصميمية، أي جوهر الحاجة الإنسانية لهذا النشاط من جهة، ومشاعر وأحاسيس البشر من جهة أخرى. وعليه يمكن تحديد مسارين لمفهوم الوظيفة: الأول يتجسد من خلال البيئة الظاهرية للناتج التصميمي وهو مرتبط بالصياغة الفنية والجمالية، وهي وسيلة لتحقيق

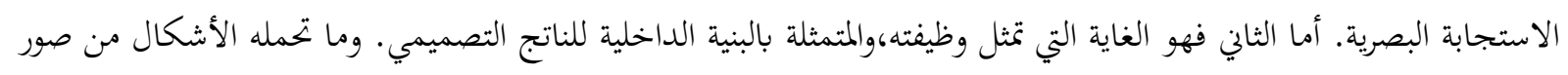
مرئية ذات معاني ودلالات رمزية معدة لغرض وظائفي، وهذان المساران لابد وان يتحدا لتحقيق الوظائفية بشكلها الصحيح

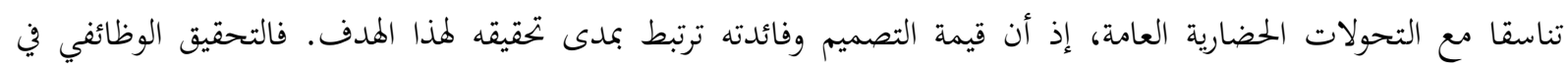


التصميم هو عملية ابتكاريه تعمل على استثارة بصر المشاهد وبصيرته.يقول "الكسندر اليوت" ((كل صورة عظيمة ترينا شيئا نبصره بالعين مع شيء ندركه بالبصيرة)).

فالجانب الأول يخضع لعملية الصياغة الفنية، وما يتضمنه من أسس وعناصر وعلاقات ترتقي بالتصميم،من خلال القيام

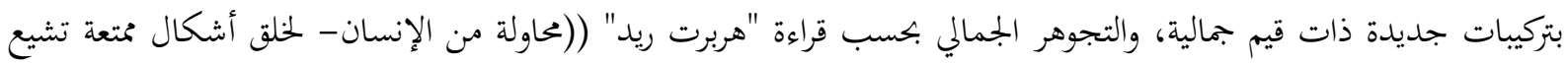

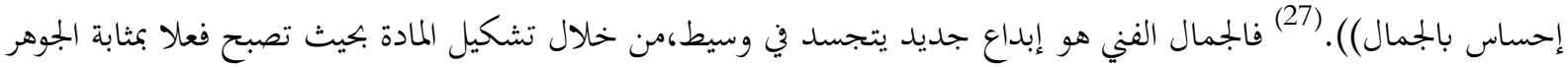
الحقيقي للعمل الفني (فكل عنصر في العمل يجب أن يؤلف مفردة ضرورية في المعنى التشبيهي، والوظيفي، والتعبيري، والجمالي الذي يهدف إله المصمم. انه الجمع الذي يوحد العناصر المنتقاة الذي يعطي العمل معناه0 ويكون باستطاعة المشاهد الذي

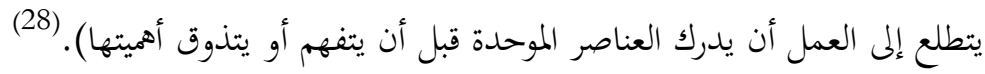
والجانب الثاني إنما يأتي من القدرة على إنتاج انساق تفسيرية جديدة، من خلال استخدام ((الوسائط التشكيلية كاللون

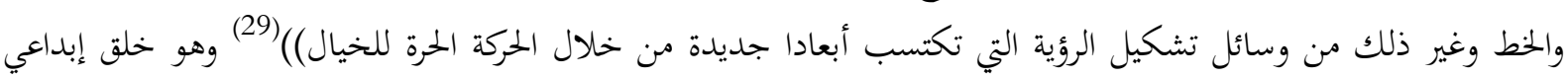

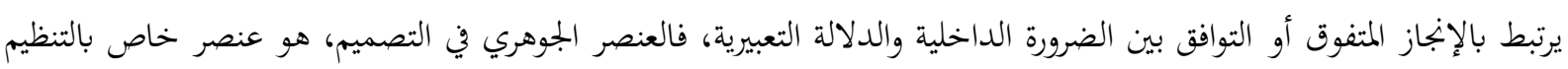

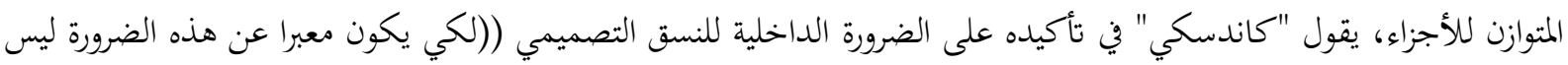

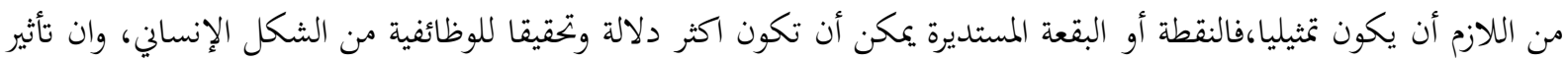

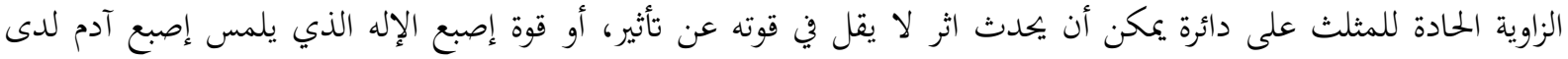

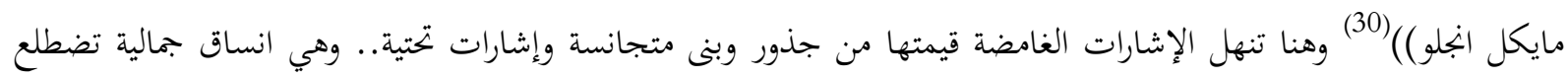

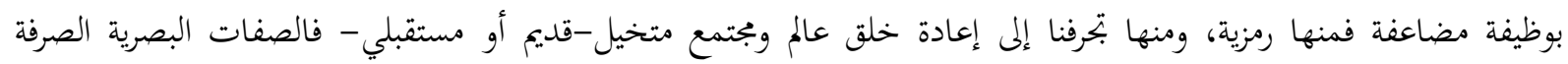
للنسق التصميمي، هي في الجوهر أقوى كل الوظائف فهي توصلنا إلى الشكل الأكثر عمقًا ومباشرة. وي ضوء ذلك فان مفهوم التصميم وبالأخص تصاميم الشعارات في الخطوط الجوية الاماراتية لم يعد محصورا بالتعريف، بل أصبح نشاطا ثقافيا بل وأصبح متحفا متجولا وهو يجمع بين الفن البصري وفن الطباعة والمكان الذي يربط بين الفن والمعرفة والعلم.

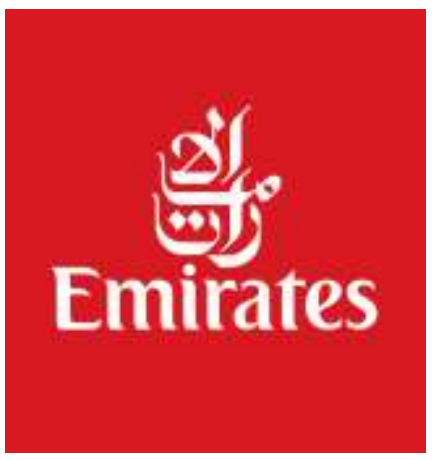

استأثر مصطلح الشكل إهتمام تحليلي متواصل في الدراسات الفنية والتصميمية ويورد الباحث جانباً من تلك التحليلات لغرض تحديد مفهومه وكما يأتي: ترى (سوزان لانجر) إن الفن هو " إبداع أشكال قابلة للإدراك الحسي بحيث تكون

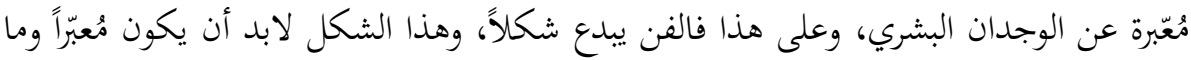

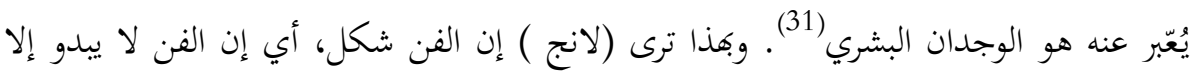
من خلال شكل ويصبح غرض الفن الأساسي هو إبداع الأشكال . وعَدَّ (سكوت) السبب الشكلي أساساً فاعلاً في العملية التصميمية إلى جانب الأسباب الثلاثة الأخرى وهي (الضرورة الإنسانية) والسبب المادي والسبب الفني التقني (32). ويعد (كاسيرير) الفن إلى جانب اللغة والأسطورة بأنه أشكال رمزية محددة للبناء الفكري ...... وإنه ليس بإمكاننا

إدراك الحقيقة إلا عبر خصوصية هذه الأشكال (33). 
ومما تقدم يُلاحظ إن الشكل رغم تعدد الإتحاهات النظرية التي حاولت إيجاد مفهوم مباشر ومحدد له، يبقى هو الصياغة

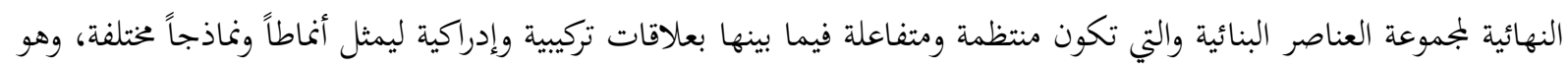

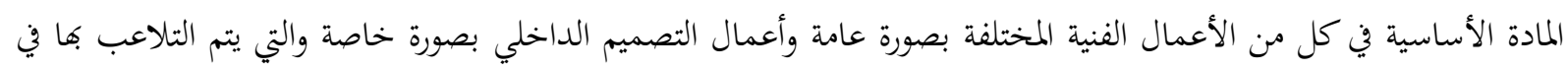
تلك الأعمال لأغراض متباينة بعض منها وظيفية والبعض الآخر منها جمالية وأخرى معنوية. ويُنظر إلى الشكل على أنه منظومة لما جانبين: 1. الجانب الظاهري ويشمل كل ما يتعلق بالوجود الفيزياوي (المادي) للشكل أي التأكيد على ماهيته والتعامل معه كظاهرة فيزياوية. 2. الجانب الفكري ويشمل كل ما يتعلق بالوجود الفكري (غير المادي) للشكل وما يحمله من القيم والأفكار والدلالات، أي التأكيد على ما يؤديه والتعامل معه كظاهرة حضارية(34). وبمعنى آخر إن دراسة مفهوم الشكل لا تقتصر فقط على الجانب المادي الذي هو محصلة الأجزاء والعناصر البنائية المترتبة على وفق علاقات منتظمة فيما بينها، ولكن تشمل الجانب الفكري للشخص الذي قام بهذا الترتيب حيث يتم إعتماد علاقات إتبات

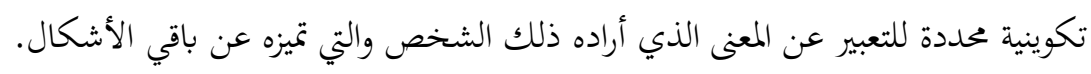

وظائف الشكل: إن للشكل طاقة تعبيرية كامنة، وتتمثل تلك الطاقة في قدرته على تحقيق وظائف جمالية تُساهم في بلورة وتشكيل هوية الفضاء الداخلي أو العمل الفني ومن تلك الوظائف: 1. الشكل يضبط إدراك المشاهد (المتلقي) ويرشده ويوجه إنتباهه في إبتحاه معين، بحيث يكون العمل واضحاً ومفهوماً وموحداً في نظره . ن. 2. الشكل يُرتبب عناصر العمل على نهو من شأنه تأكيد قيمتها الحسية والتعبيرية وزيادتما . 3. التنظيم الشكلي في حد ذاته له قيمة جمالية كاملة 35. فالشكل يوجه إدراك المشاهد ويجذب إنتباهه إليه كجزء من عملية التذوق الفني والجمالي للشكل، كما إن قيمة التذوق

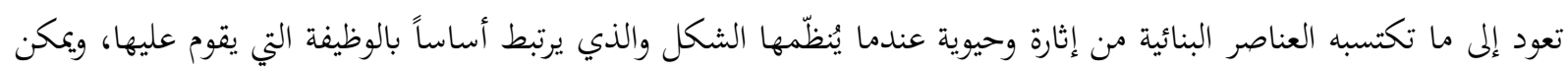

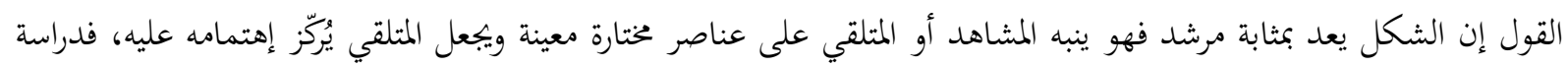

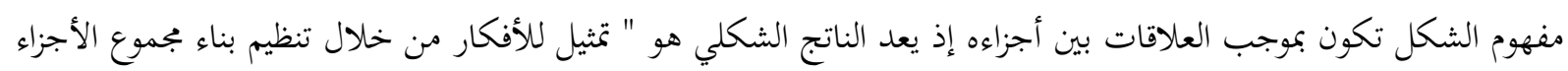
وعلاقات ربطها التبادلية لإدراك الشكل المرئي "

فالشكل في التصميم تتميز فيه النظم بوحدة متكاملة تعبر عن موضوع ماله تركيبته البنائية، وعناصره الأساسية التي لا

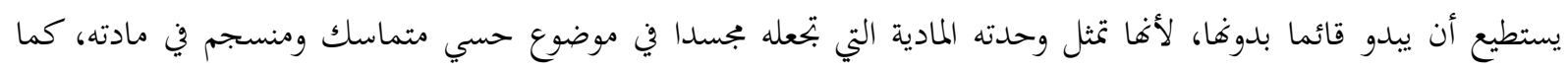
ينطوي على مدلوله الباطني، ويعبر من جهة أخرى عن حقيقة روحية يشعر بها المتلقي وفق قدراته، خارج واقعة الملموس. وبهذا فأن الشكل هو الصورة المادية المحسوسة واتتي تشير إلى صورة ذهنية تتجلى هذه الصورة من خلال مادة الشكل. وهنا يكمن حوار الرؤية بين كل من الشكل والمضمون. (الشكل هو العنصر الأساسي والاهم في الفن، بينما المختوى هو بمثابة العنصر الثانوي الناقص الذي ليست له القدرة على الإحاطة بكل جوانب الواقع)). (36) 
إن صياغة الشكل بصورته الدلالية تعد عملية فكرية وإبداعية في تكوين أشكال جديدة قابلة للإدراك الحسي، عن

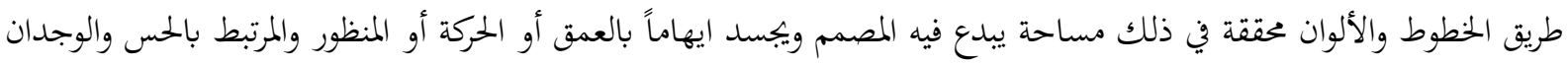

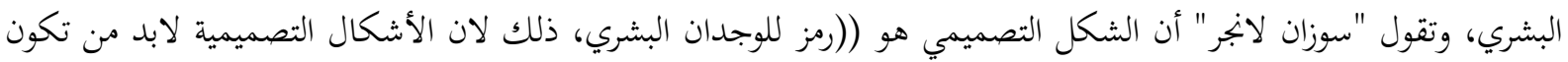

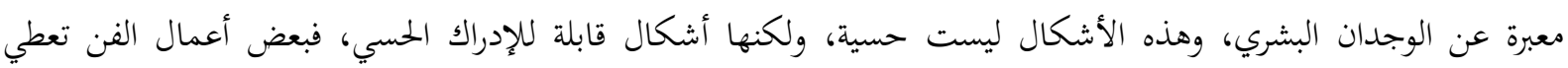
للخيال))(37). ومن هنا يصبح الشكل كرمز دالا على شيء ليس له وجه شبه، وهذا ما يتحقق في كثير من الأعمال التصميمية، كالعلامات التجارية والعلامات التي ترتقي إلى أن تكون شعارات معتمدة لشركات أو مؤسسات إعلامية لتهية أو غيرها،

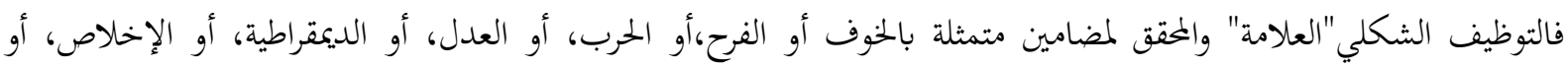

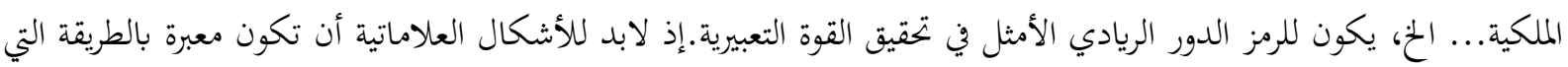

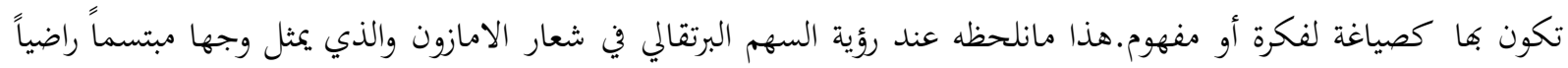

\section{amazon ذلك أن للشكل العلاماتي كيان خاص هذا ماسعت إليه الشركة

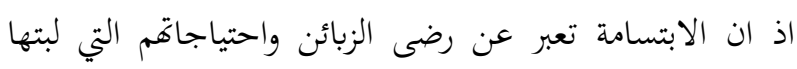

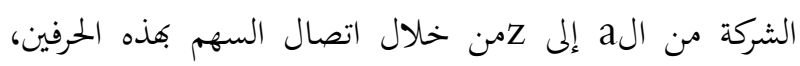

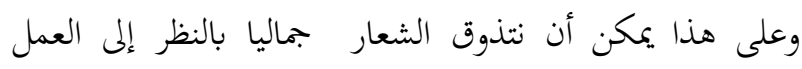 ذاته،والى جماله الباطني، ووحدته وفاعليته.}

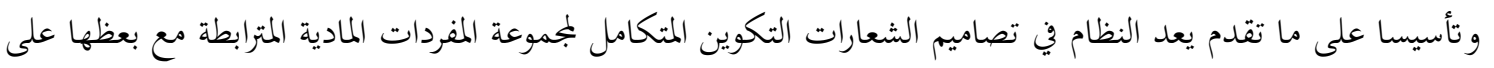
وفق قواعد معينة لتشكل مفهوما ذا خواص مميزه، فالتكوين بالنتيجة شكل form مستند إلى كل المفردات الداخلة في بناءه،

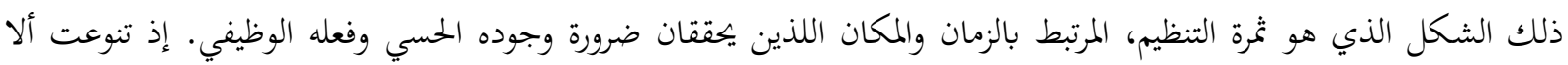

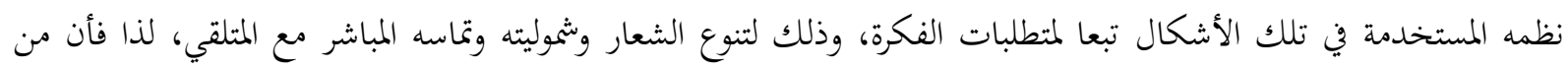

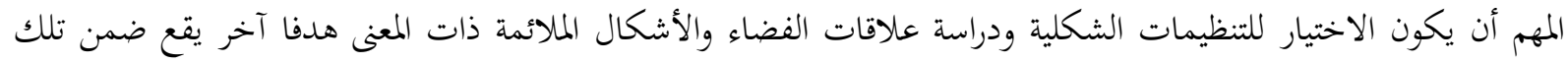
الأهداف وهو تصميم النظام ((العمل التصميمي هونتاج إنسان ينظم فيه المواد بحذق ومهارة لكي يوصل بتحبة إنسانية ما))( (38).

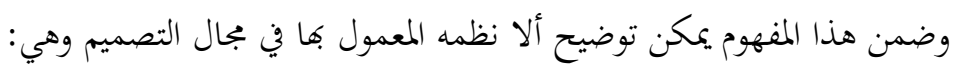

$$
\text { • }
$$

$$
\text { • • النظام الخطي. }
$$

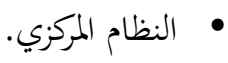

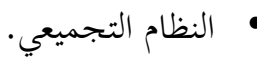

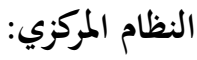

ويمثل هذا النوع من الأنظمة بالتنظيمات المتمركزة حول ذاها، والمتألفة من أشكال أخرى متمركزة حول الأشكال الأصلية السائدة، والتي تختلف عن بعضها البعض في الشكل والحجم، تبعا للمتطلبات الوظيفية، والمتطلبات التصميمية الأخرى. ويتسم

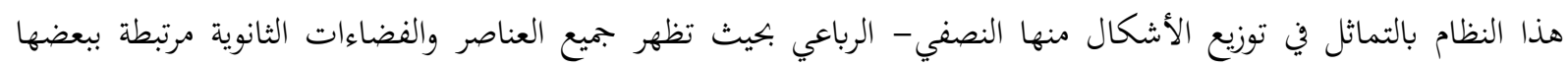

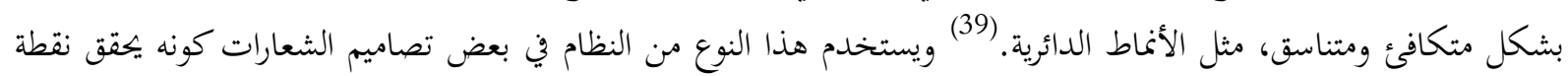
استقطاب المشاهد نخو الشكل. 


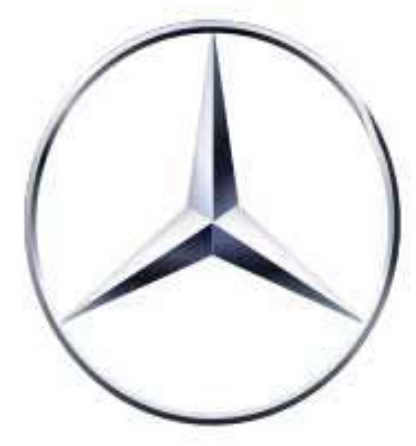

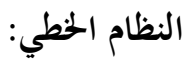

وتتوزع فيه العناصر التشكيلية على هيأة خط مستمر أو متقطع أو مستقيم أو مائل، منحن أو منكسر، وترتبط

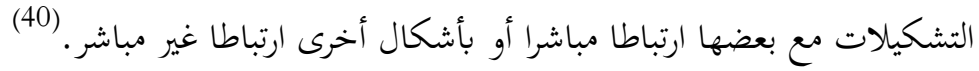

وهذا النوع من النظام يعطي إيهاء بالحركة والاتحاه والاستمرارية والاستطالة والنمو الناتج من تكرار وامتداد الأشكال

الخطية، محققة في ذلك (حركة في المجال المرئي). (41)

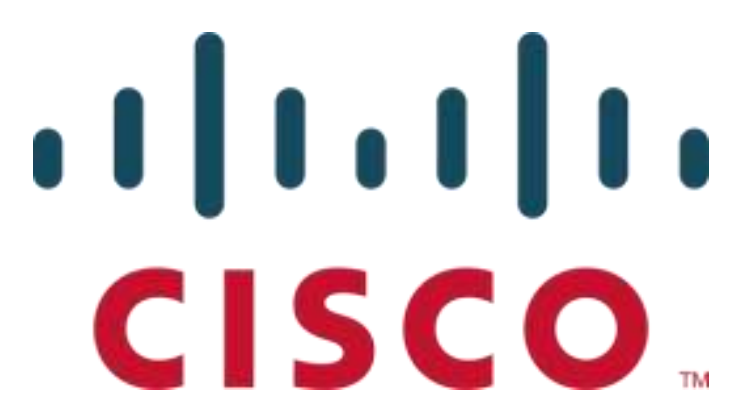

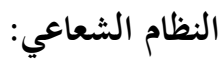

يتميز هذا النوع من النظام في العملية التصميمية بالإيحاء الحركي معتمدا الاتحاهات الخطية بطريقة إثعاعية، وهو يجمع بين

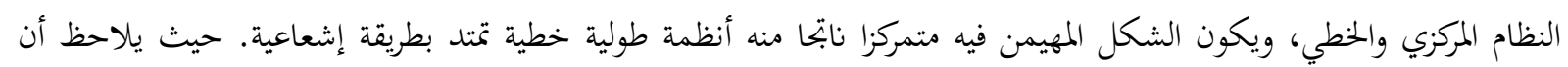

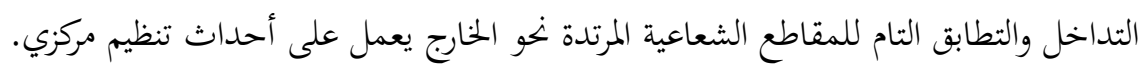

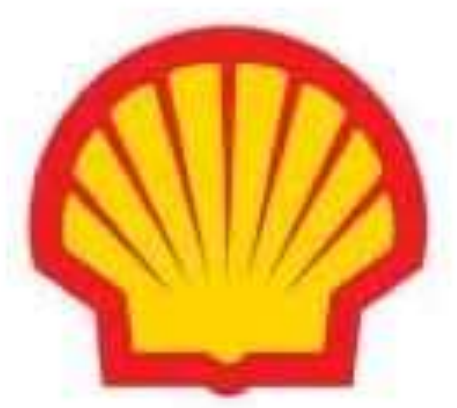




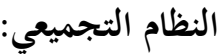

ويخضع هذا النظام إلى التجمع الشكلي المترابط والمتناسق أو المحوري، إلا أنه توزيع غير هندسي حيث يتم تجميع الأشكال

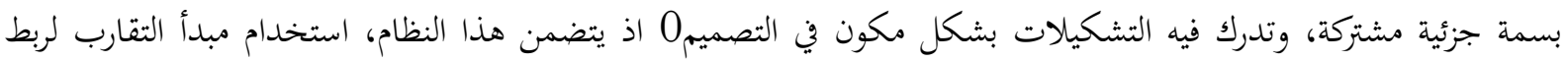
العناصر مع بعضها البعض ويتضمن أيضا مبدأ التكرار.

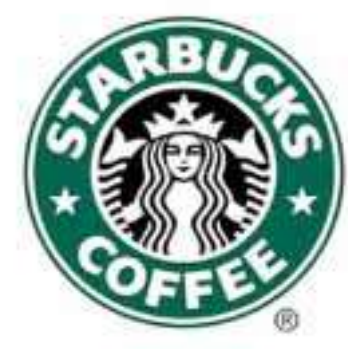

وهو نمط من الأنظمة المرنة التي تتقبل النمو والتغير دون التأثر بالطابع العام.

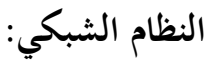

ويتمتع هذا النوع من النظام بالقدرة على توزيع الأشكال على وفق تنظيم خطي متقاطع اشبه بنظام الشبكة، ويحتوي على

مفردات داخل مجاله المرئي. (42)

وخاصية التقطيع للفضاءات داخل حدود الشبكة تعزز من مركزية هذا التنظيم وتحقق حركة مستمرة في المجال المرئي.

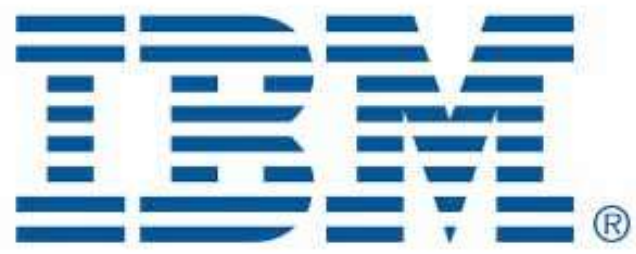

إن عملية تحقيق النظام في العملية التصميمية، سواء كان نظاما مركزيا، أو نظاماً خطياً أو غير ذلك من الأنظمة، إنما هي عملية تعمل على توحيد العناصر والتي يستخدمها المصمم في بناء متداخل ومتماسك والمجسد في الشعارات، وقد يساعد التهاء التكرار

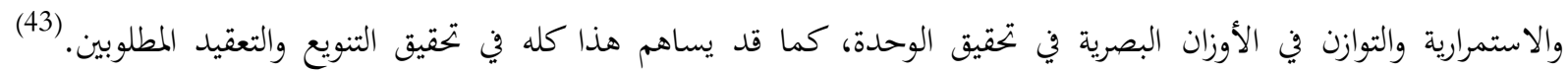

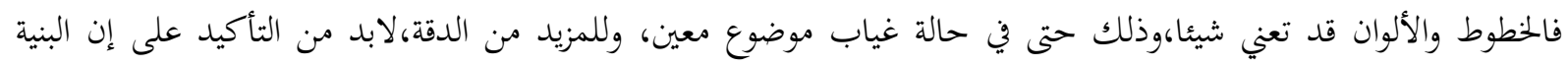

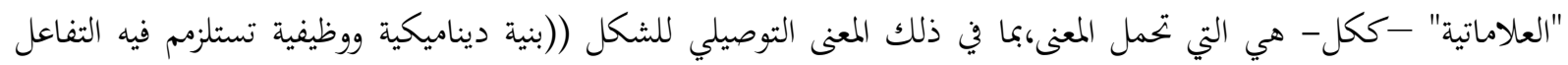

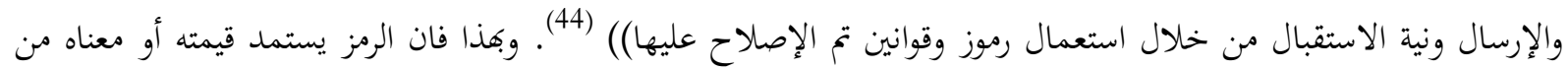

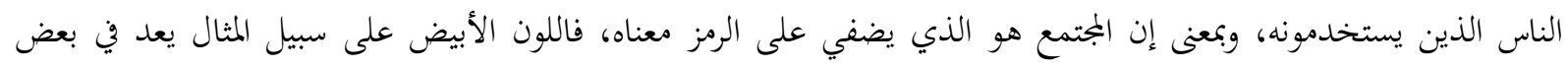

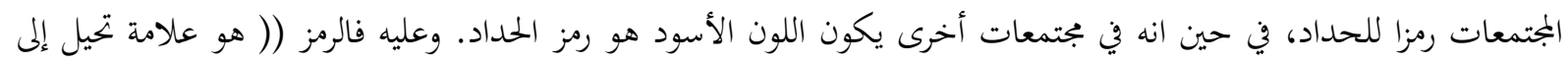

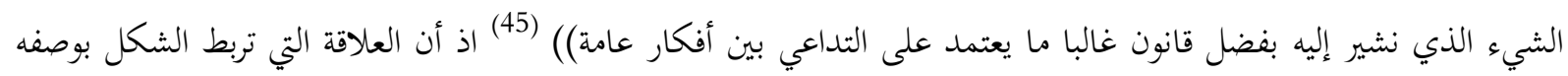

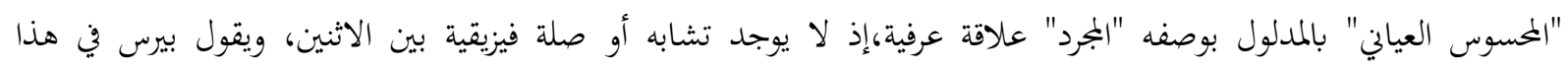

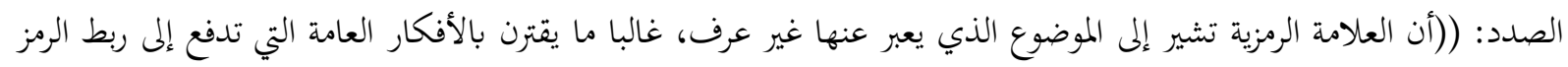

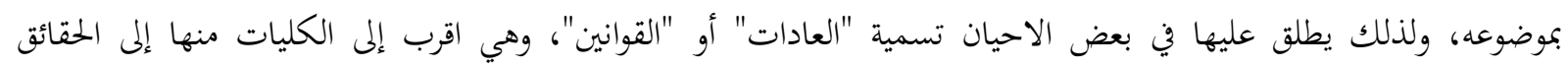


المتحققة،ويمكن القول إفها تجليات للرمز نفسه،مثل ارتباط الحمامة البيضاء بالسلام، والشمس بالحرية)) (46). ويعد من بين أنواع

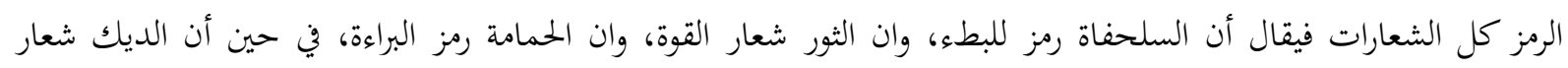
للحذر.

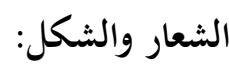

إن عملية الوعي للشكل وتوظيفه، ليضحى نظاماً دلالياً (إشاريا أو رمزيا) متفقا على بثه ومعانيه، ترتبط بمستوى الإدراك وصورته الزمكانية.

فالشكل Form هو الأساس والمنطلق، والوعي به هو بداية التشكيل وحركته. وفي الشعار نجد أن الشكل هو عملية بناء

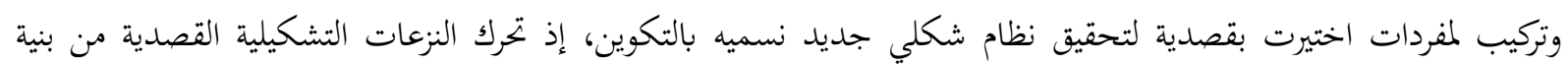

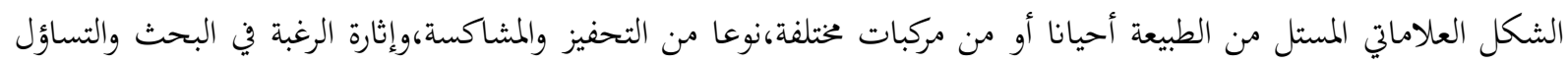
والكشف والانتقاء.فقدم التأويل في الشكل،وهي عملية تشكيل أنظمة جديدة يعتمدها المصمم في نسيج علاقاتها المختلفة. وعليه فان التكوينات الشكلية العلاماتية المتمثلة بّ"الشعارات" تقع ضمن ((العمليات التركيبية لأشكال جزئية منفردة أو

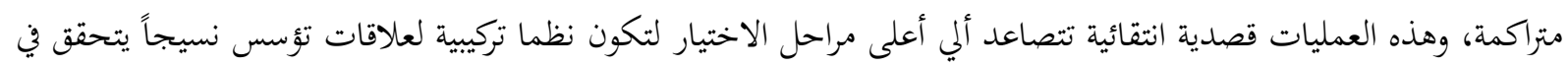

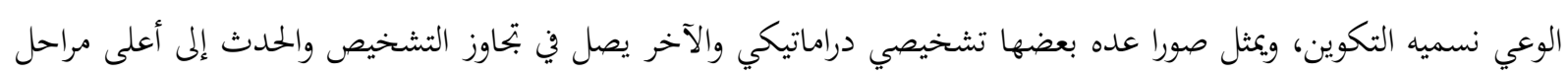

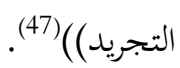

و تأسيسا على ذلك نجدان الشكل العلاماتي المتجسد في "الشعار"يعد شكلاً من أشكال التنظيم الواعي في تحقيق تأثيرات

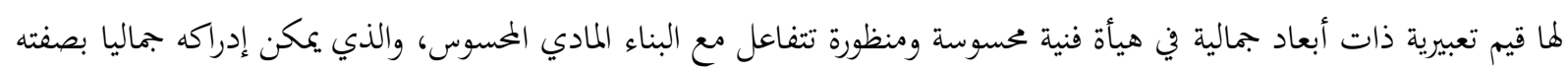
الشيء المنبثق من عملية التجسيد للوحدات البصرية الخاضعة للنظام القصدي. ولاجل هذا فان اقتراح الأنظمة التصميمية وتحقيق علاقاتما في الشكل العلاماتي"الشعار" يبقى يدور في الكيفية التي

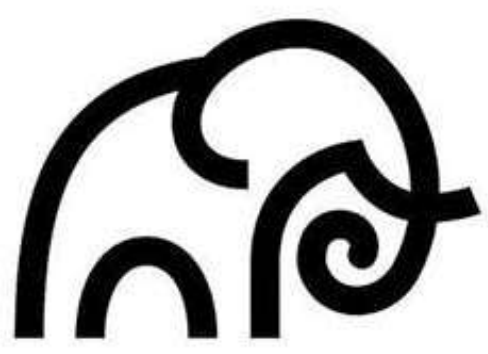

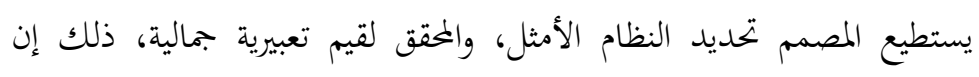

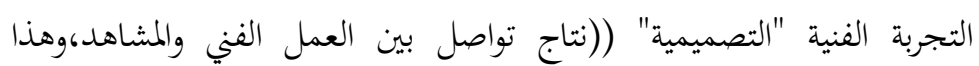

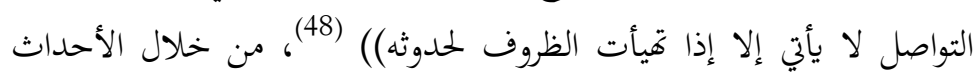
الحاصلة على سطح التصميم. وعليه فأن الاختيارات القصدية لتكوينات تنظيمية قد تتمثل بتكوينات انتشارية أو ايقاعية (محورية، مركزية، قطبية) هي اختيارات تحدد فاعلية التنظيم الشكلي في تصاميم الشعارات ودلالاتما. فالشعار بدلالته يعد عملية اتصال فعالة بينه وبين المتلقي من خلال التأثيرات الشكلية الحاصلة في بنية الشعار. (إذ يمكن أن

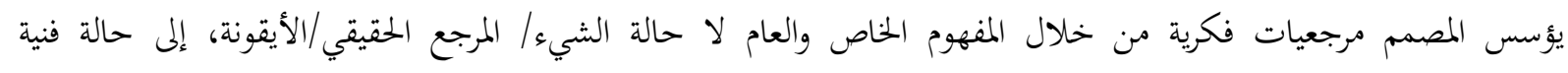

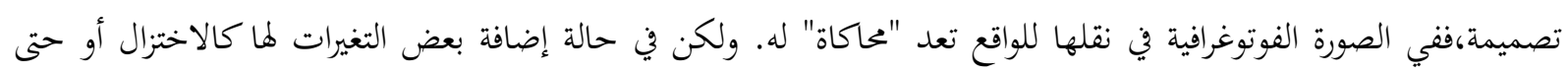
التشويش، أي خروجها عن المرجع تمهيدا لاحلال صورة فنية محل الصورة الشيئة، أي الذهاب إلى ما وراء البصر باتحاه الذهن.

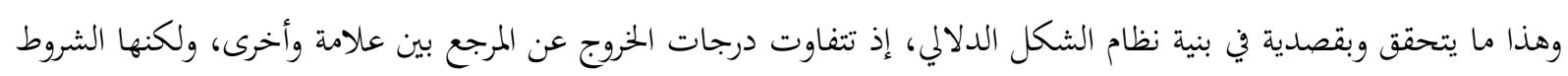
أو (الضرورة) بالمفهوم الفلسفي، ليكسب "الشعار" المشروعية التصميمية) (49). 
وهكذا ففي بنية نظام الشكل الدلالي في بعض شعارات الخطوط الجوية (لا تخضع العلاقات لتحديدات مرجعية بعينها بل تنفتح

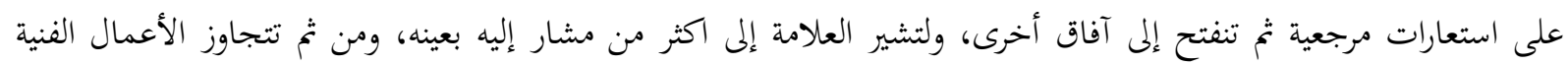

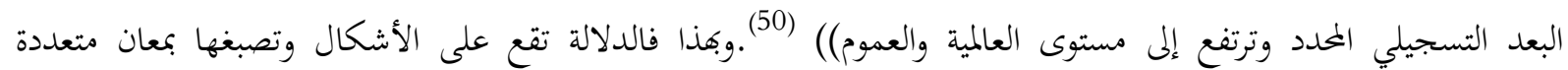

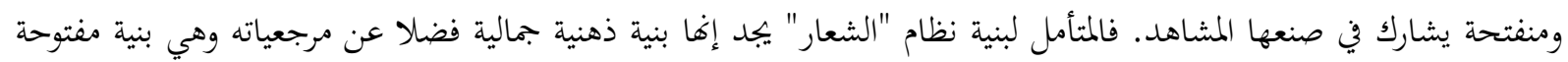
على التاويل.في إنتاج المعنى كما في شعار الطيران الكندي حيث حسئ جاءت الاستعارة الشكلية استعارة أيقونة، فيما جاءت الاستعارة الشكلية لشركة الطيران TAG مختزلة وهي مختصر لكلمة (تشالنجر) حيث جسدت الرمز الدلالي.

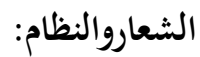

الشعار عبارة عن تكوين صغير الحجم يعبر عن معان ودلالات،يخضع إلى المعايير الفنية التصميميه والعلمية في فن الرسم

والخط والإخراج، ويحتاج إلى دقة في اختيار العناصر من حيث حروف الاسم ونوعها والخطوط والمساحات اللونية،فهو يعبر عن الفكرة ومضموها وهو يمثل العلامة التجارية للشركة، وتتصف بنية نظام الشعار بمواصفات بتعله سهل التذكر والتعلق بالذاكرة.

ومن هذه المواصفات هي: (51)

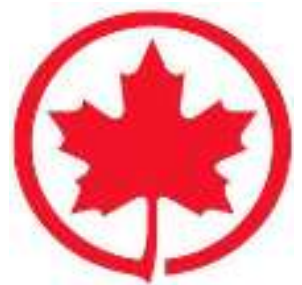

1. الملاءمة: حيث يتمتع الشعار بملاءمة محتواه من حيث المفردة الداخلة في تكوينه كان تكون حرفًا

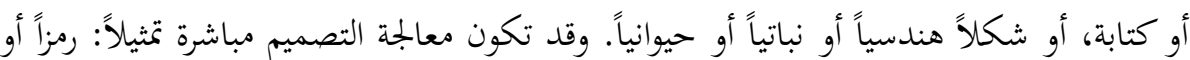

تجريداً بجتاً مع غرض شركة الخطوط الجوية والطبيعية العامة.

2. الإبداع: أن يكون الشعار من النوع الإبداعي واضح التميز والتفرد عن تلك المستخدمة في الشركات الأخرى التي بنفس الخط الإنتاجي في الأقل.

3. البساطة: آن يتميز الشعار بالبساطة، كي يعرف من لمحة واحدة مراعاة لزمن التلقي

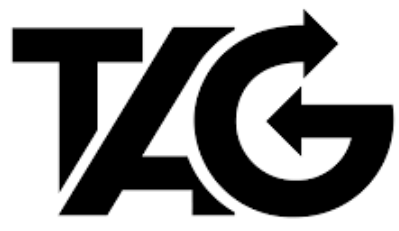

اللحظي.

4. المعاصرة: آي أن يعكس تصميم الشعار حسا معاصرا وله جاذبية تستجيب

لكقياسات الفنية المؤثرة اجتماعيا.

5. الجاذبية: أن يكون جاذب للمظهر، من حيث الاستجابة للاستعمال المرن قدر

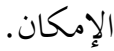

6. التذكر : أن يتضح الشعار بقوة الانطباع الدائم وان ينظر على نحو كاف لكي يتذكر.

7. النفعية: له إمكانية للاستعمال المرن وان يكون حيوياً وفعالاً.

8. المحلية: وفيها تتم معالجة البنية الشكلية"الشعار" بما يؤشر سمات محلية دون أن ينقطع كليا عن حس العالمية، أي أن يحقق

التوافق بين الملامح المحلية والتطلعات العالمية.

كما ويصنف الشعار على وفق طبيعته وعلى ضوء استخدامه كالآتي (52):-

أ. شعارات تأخذ هيأتها من الحرف، حيث تلجأ بعض المؤسسات أو الشركات إلى استخدام الحرف الأول من اسمها رمز يمثل 


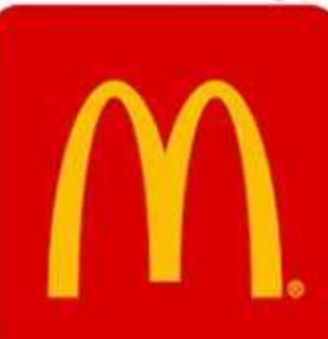

ب- شعارات تأخذ حروفها أو علاماتما الكتابية أي يعطي الاسم الكتابي للشركة.

\section{Callon}

ج. الشعارات التي تكون صورة مشتركة بين شكلين أو اكثر.

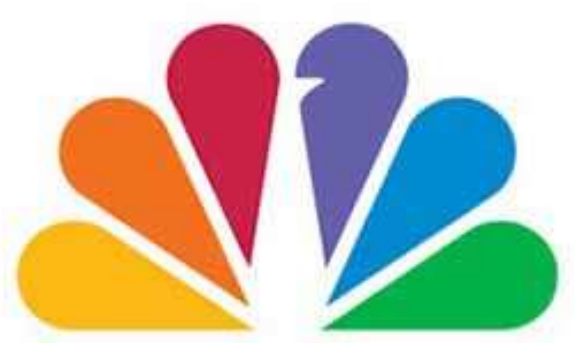

د. الشعارات التي تركب من الحروف والأشكال في آن واحد.

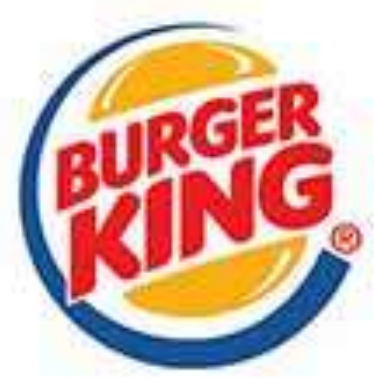

و تأسيسا على ما تقدم يمكن القول: إن كثيراً من المصممين يميلون إلى سمة التنوع الشكلي في تصاميم شعارات الخطوط الجوية العربية وغير العربية المتأتية من شرط (اللاتشابه) مع الشعارات الأخرى، فضلا عن من (اللاتطابق) تحقيقا لمبدأ التفرد للشعار. إلا أن سمة التعبير تعد الهدف الأول الذي يعنى المصمم بتحقيقه من خلال تظافر ثلاثة متغيرات فاعلة وأساسية-كما يحلدها " عبد الرضا بكية "وهي:- (53) 1. عناصر بناء شكل الشعار (متغيرات النظام الخاص). 
2. العوامل الساندة وهي: جملة المقاربات السيميائية وقوانين الجشطالت، التقنية التنفيذية فضلا عن طبيعة العلاقات بين العناصر

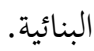

3. الأنساق البنيوية: وهي الاختيارات المرجحة للمصممم بشان مواصفات الطابع الشكلي من قبيل: النسق الهندسي،النسق ألا يقوني، النسق الحر وفي، والنسق المختلط.

\section{النتائج ومناقشتها:}

1. تحقق ادراك النظام التصميمي في جميع الشعارات، وذلك لوضوح الرسالة التصميمية التي أرسلها المصمم للمتلقي من خلال

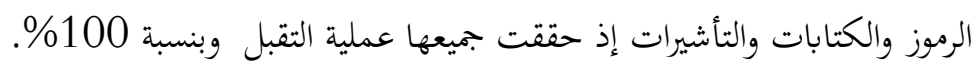

2. أظهر موضوع الشعار من حيث كونه لغة دلالية مرمزة أفكاراً مختلفة ترتبط بمحدد ثقافي تقترحه المؤسسة، أو الشركة. فالشعار

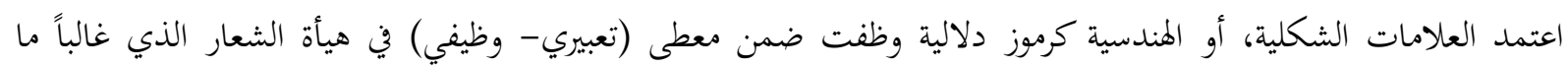

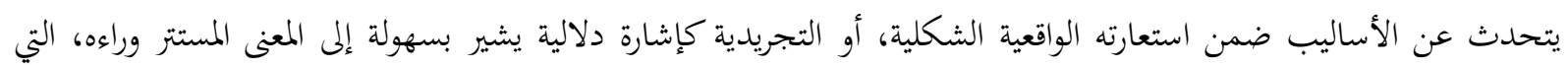
تكون خاضعة لمتطلبات الفكرة المرتبطة حتماً بالمحددات الوظيفية. 3. اعتمد التنظيم الشكلي على مجموعة من الأصول والمرجعيات ومدركات عقلية أسهمت استدراك الشكل في الشعات الشعارات, قد فـ

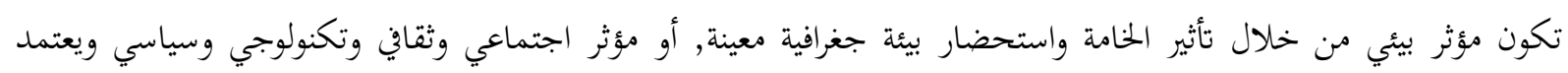
الرجوع إلى هذه المرجعيات إلى طبيعة وثقافة المصمم والبيئة المحيطة .

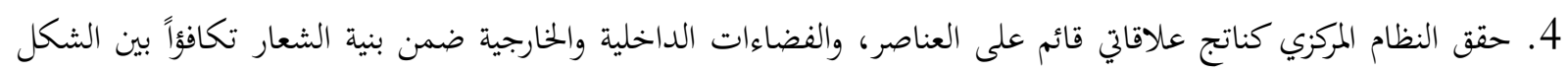

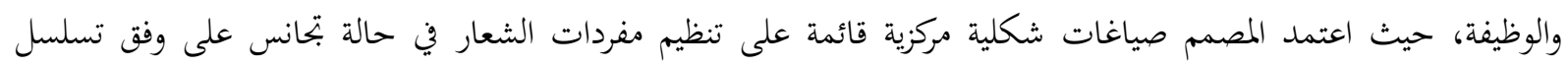
منطقي في ربط تلك المفردات مع بعضها البعض لتحقيق نقطة الاستقطاب البصري حول نقطة مركزية تعد الأساس في إيصال المعنى الشكلي، واستدلاله. 5. حقق النظام الخطي تأليفاً، واتساقًا بين العناصر، والأسس كافة الداخلة ضمن بنية تصميم الشعار كما هو في العينة (ibm)

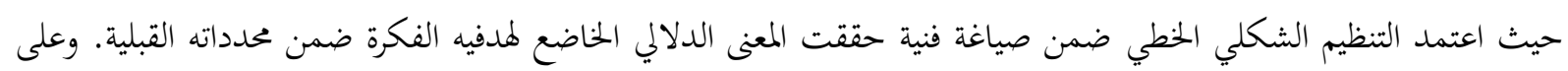

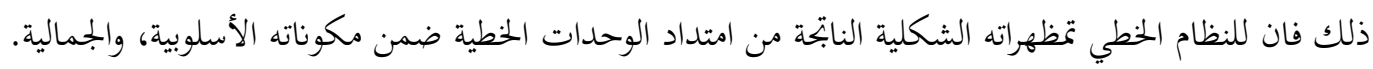

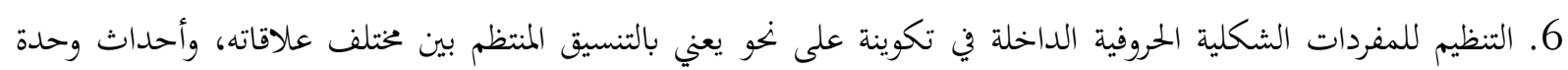

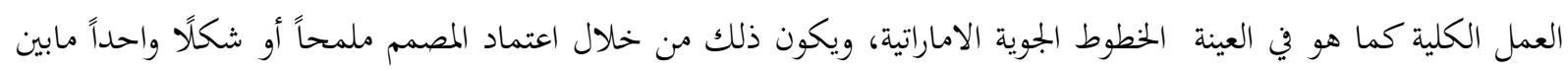
الحروف العربية واللاتينية. 7. حققت الشعارات قيمتها الفنية من خلال عمليات التنظيم، وظهر النظام التجميعي في ترابط بين الأشكال التي جاءت مستعارة من الواقع ضمن عملية بتميعية تدرك بشكل مكون تصميمي من النظام يعطي إيحاء بالحركة والاتجاه والاستمرارية

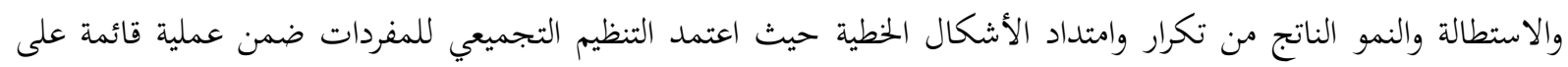
التقارب في ربط تلك المفردات مع بعضها البعض في أحداث التكامل ما بين الأشكال المختلفة لتجسد التكوين الشامل. 
1. يمكن المزج بين نظامين لتعريف الهوية هما نظام كلي يدلل على هوية وظيفية تقليدية ونظام كلي من خلال العناصر ضمن المشهد الاستدلالي الشكلي الذي يجسد طراز ين معين. 2. يتعزز الرمز في الشعار في احالة الصورة الذهنية إلى وجود عياني مسبق ذو طابع استدلالي تعبيري عن رموز تعزز وبحسد الهوية الوطنية. 3. العلامات الشكلية أو الهندسية كرموز دلالية جسدت المعنى الاستدلالي الشكلي التعبيري المرتبط بالوظيفة. 4. يتيح الاعتماد على أنظمة الألوان الحارة والتباين اللوني استدلالا بين المرئيات وإظهارها كمناطق إثارة وتحفيز بصري, وإدراك

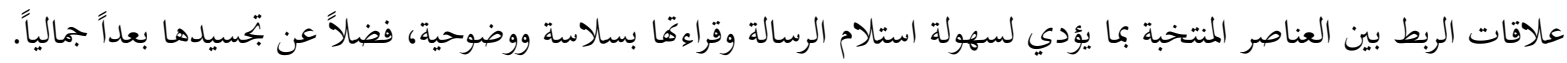
5. يمكن المزج بين نظامين للتجسيد وتعزيز الاستدلال الشكلي، كالنظام الشكلي المرتبط مع النظام الحروفي وهما نظامان يدلل

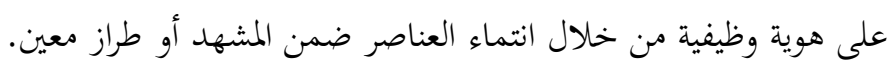

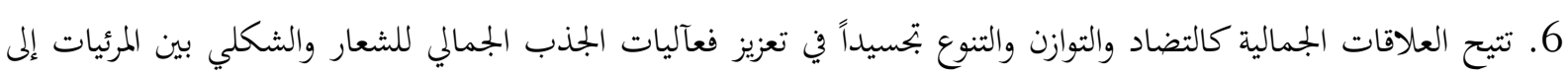

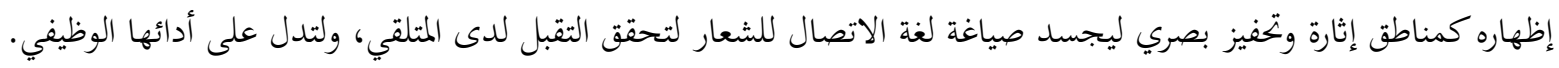

التوصيات: 1. تأكيد التمثيل الايجابي للسمات الممثلة لهوية المجتمع أو البيئة المخيطة من خلال عمليات التنظيم الشكلي ودلالاته ضمن تحقيق أساس الوحدة والتنوع للشعارات.

2. الاهتمام بعمليات توظيف الرموز والأشكال ذات الاستدلال الذي يعزز الهوية سواء كانت مفردة أو متعددة لما لما من اهمية في

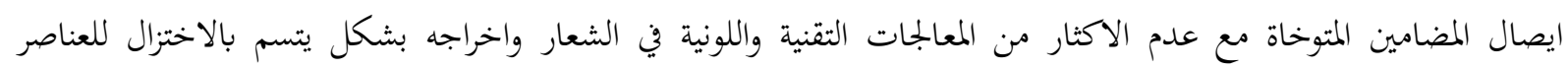

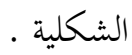

المقترحات:

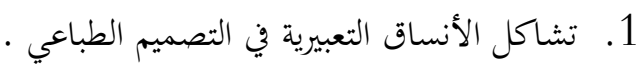
2. - 2. - التحول الدلالي في الشعارات التجارية . 
(1) جميل صلبا ، المعجم الفلسفي الجزء الاول، دار الكتاب اللبناني ،بيروت لبنان،1982م،ص 471.

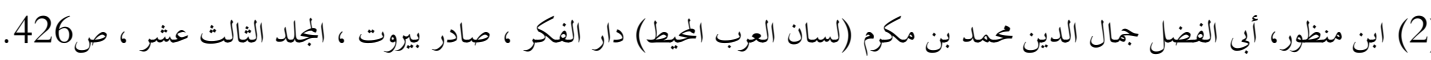

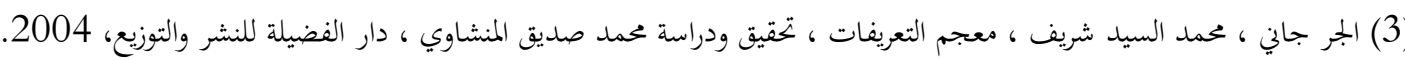

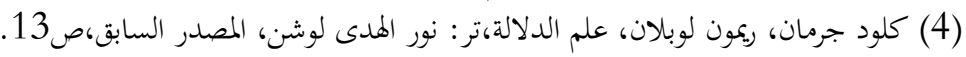

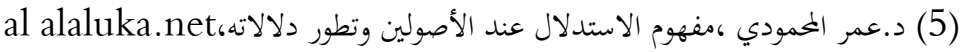

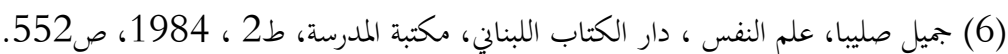

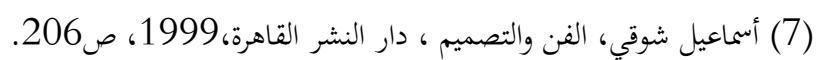

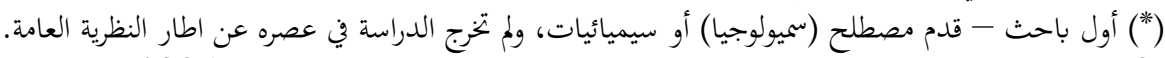

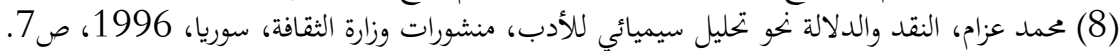

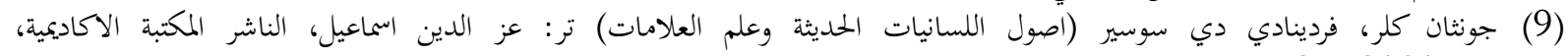

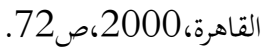

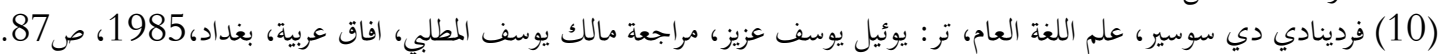

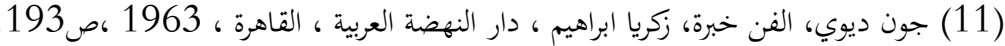

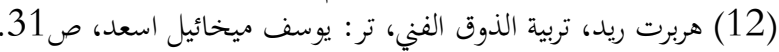

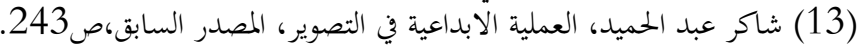

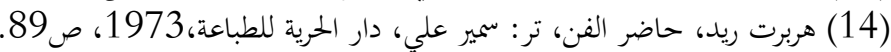

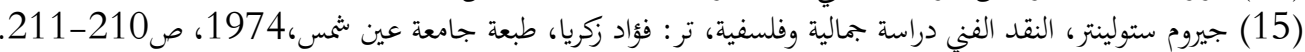

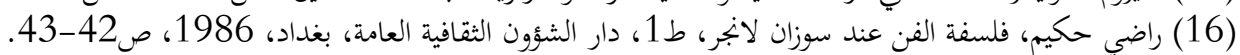

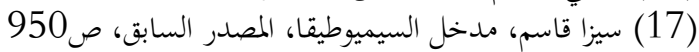

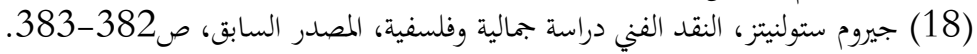

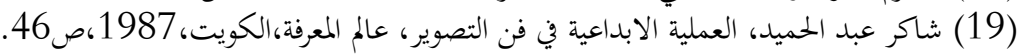

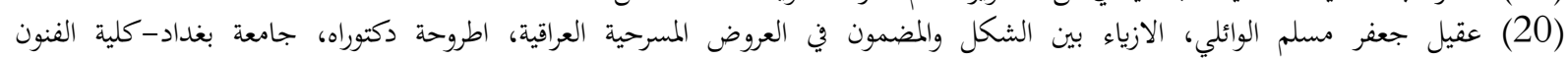

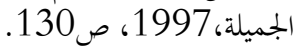

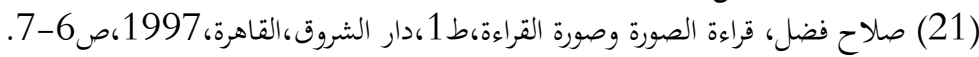

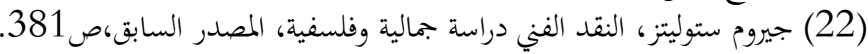

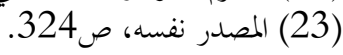
(24) عبد الرضا بهية داود، دور المعالجات الادراكية في اختزال البنية التصميمية للعلامة التجارية، بجلة الاكاديمي، كلية الفنون الجميلة- جامعة بغداد،

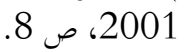

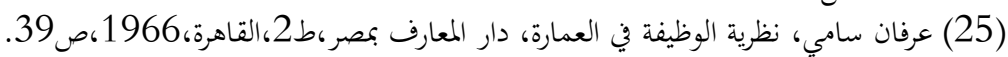

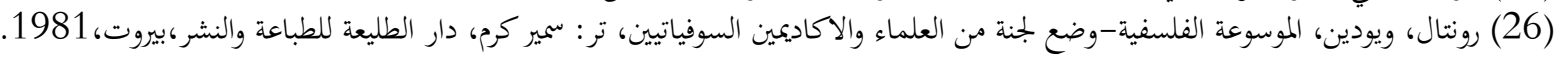

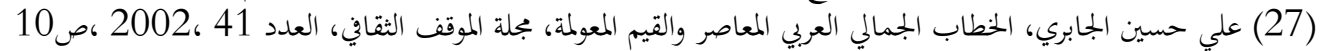

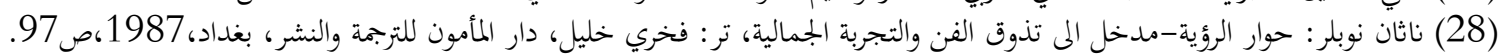

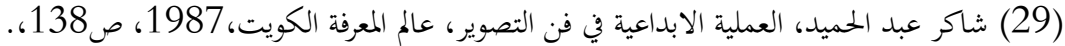

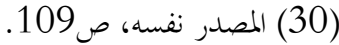

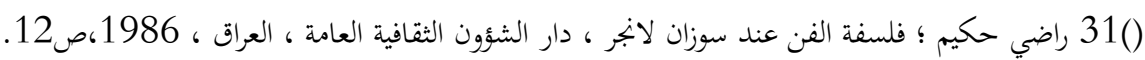

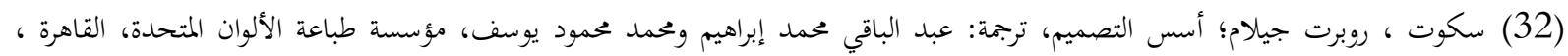

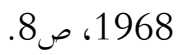

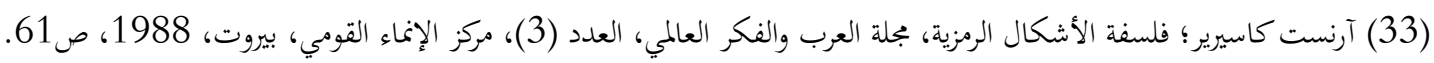

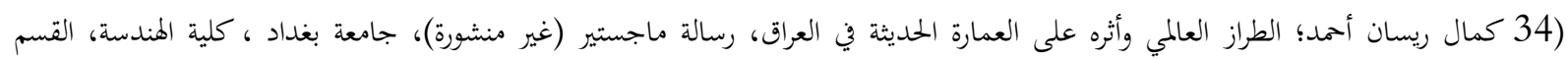

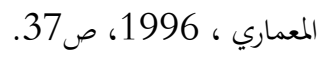

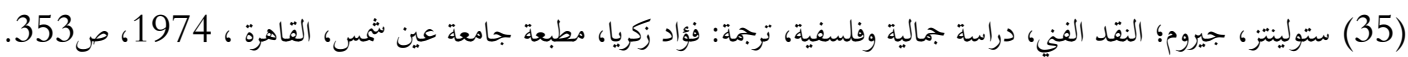

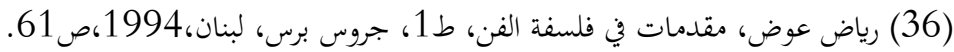

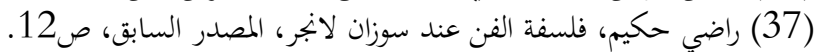

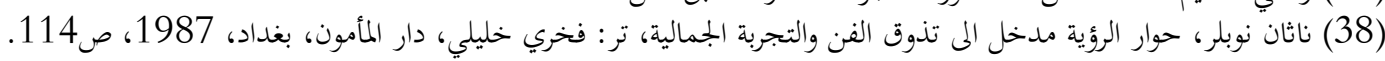

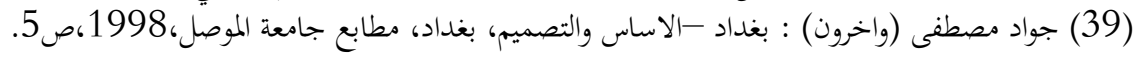




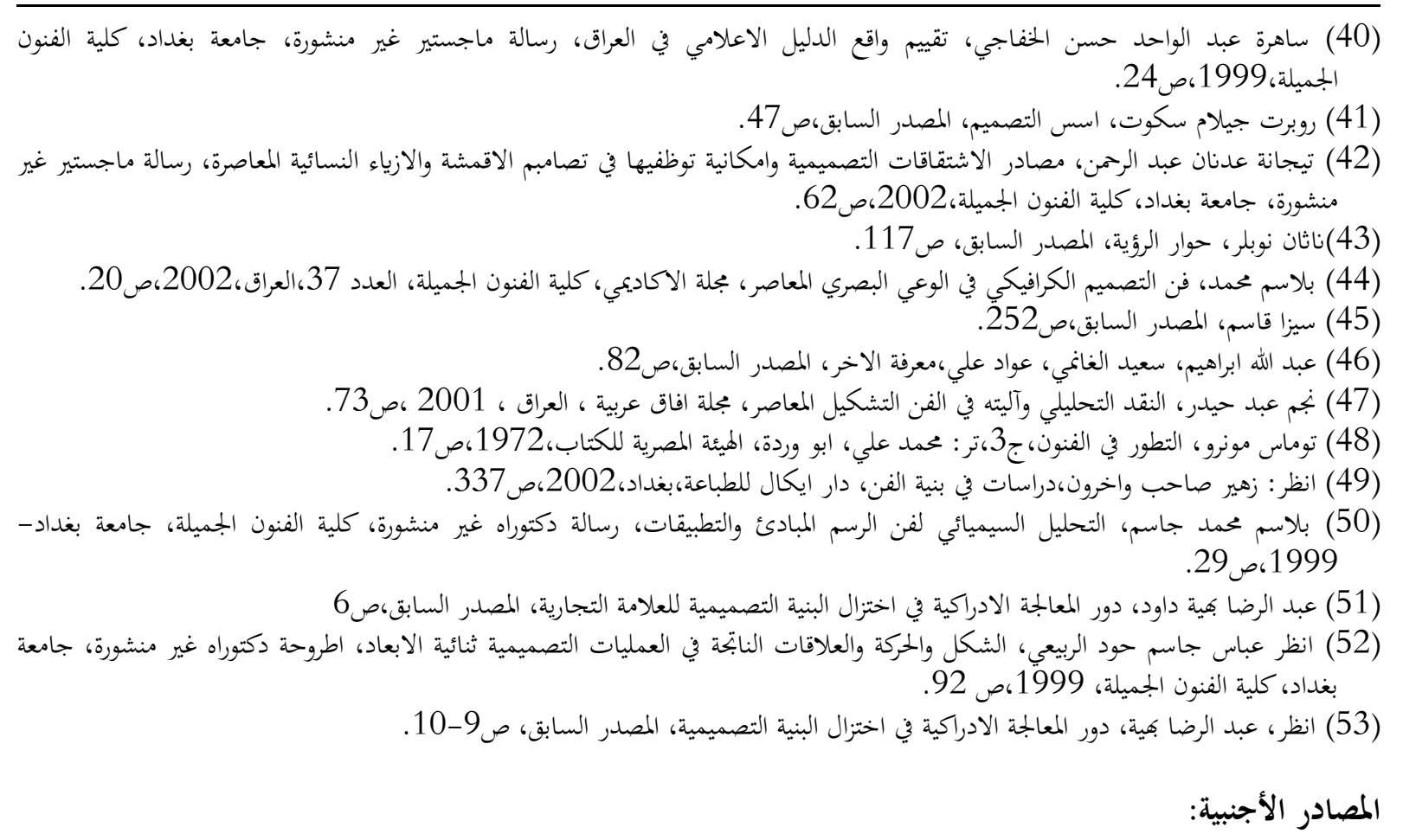

$\left({ }^{53}\right)$ Horrby, A,S.\&Paruwell,E,C,((Oxford:An English Readers Dictionary)),Oxford Un Iversity Prees, London ,18th Impression,1967,P444.

$\left({ }^{53}\right)$ Lobell, John, Between Silence and Light ,Spirit in the Architecture of Louis 1. Kahn Shambhala Boulder, 1979.p.p 56.

(2) Arnhiem, Rudolf, the dynamics of Architectural ,Univ of California Press, California, $1977, \mathrm{p} 135$.

${ }^{(53)}$ http://www. n:zwa.com /volume 34 /p122 128. htm1

$\left({ }^{53}\right)$ Arnheim, Rudolf , Art Visual Perception of the Creative eye , Berkeley University of Californi , 1974,p172.

${ }^{(53)}$ Ching ,Francis.D.K.:Interior Design,.New york..Van Nostrand Reinhold company, 1987.P.201

${ }^{(53)}$ Ching, Francis.D.K.:Interior Design,.New york..Van Nostrand Reinhold company, 1987. P.204

53 Ching, Francis.D.K.:Interior Design,.New york..Van Nostrand Reinhold company, 1987. P.204 